\title{
A standardized description of European Sminthuridae (Collembola, Symphypleona), 3: description of seven species of Sminthurus, including four new to science
}

\author{
Pierre Nayrolles \\ Laboratoire de Zoologie, Ecobiologie des Arthropodes édaphiques, Université Paul Sabatier, 118 route \\ de Narbonne, F-31062 Toulouse Cedex, France
}
Keywords: Collembola, Symphypleona, Sminthurus, chaetotaxy, new species, taxonomy, ontogeny, France, Spain

\begin{abstract}
The following three species are redescribed: Sminthurus viridis (Linnaeus, 1758), Sminthurus nigromaculatus Tullberg, 1871, and Sminthurus multipunctatus Schäffer, 1896. Four new species are described from France and Spain: Sminthurus bourgeoisi n. sp., Sminthurus bozoulensis n. sp., Sminthurus leucomelanus n. sp., and Sminthurus hispanicus n. sp. The importance of the ontogeny of chaetotaxy is stressed. Indeed, not all species acquire the secondary chaetotaxy in the same instar, and for these characters the most informative instar is not the adult but the third juvenile instar. The study of such characters involves the clustering of similar characters. A short discussion is given about this issue (selection of characters and clustering criteria).
\end{abstract}

\section{Résumé}

Les espèces suivantes sont redécrites: Sminthurus viridis (Linnaeus, 1758), Sminthurus nigromaculatus Tullberg, 1871 et Sminthurus multipunctatus Schäffer, 1896. Quatre nouvelles espèces sont décrites de France et d'Espagne: Sminthurus bourgeoisi n. sp., Sminthurus bozoulensis n. sp., Sminthurus leucomelanus n. sp. et Sminthurus hispanicus n. sp. Nous attirons l'attention sur l'étude de l'ontogenèse de la chétotaxie. En effet, toutes les espèces n'acquièrent pas leur chétotaxie secondaire au même stade. Aussi pour de tels caractères, le stade le plus intéressant n'est pas l'adulte mais le juvénile de troisième stade. Pour être utilisés, ces caractères demandent à être agrégés lorsqu'ils présentent des similitudes. Un bref aperçu sur ce sujet est proposé: choix des caractères, critères de regroupement.

\section{Introduction}

This is the third part of a series dealing with the European Sminthuridae. The standard of descrip- tion proposed in the first paper (Nayrolles, 1993a) will be used here again.

Sminthurus Latreille, 1804 is the most ancient genus of Symphypleona. The genus was heterogeneous, and progressively species were transferred to different genera. The last review of the genus was by Betsch $\&$ Betsch-Pinot in 1984. Within the subfamily Sminthurinae, these authors distinguished three genera sharing the character "presence of a pair of postantennal setae"'. These genera, Allacma Börner, 1906, Spatulosminthurus Betsch \& BetschPinot, 1984, and Sminthurus Latreille, 1804, sensu Betsch \& Betsch-Pinot, 1984 were well established, because each one was defined by evolved characters, making it monophyletic. In my previous paper (Nayrolles, 1994), dealing with the monophyly of the group Allacma-Spatulosminthurus-Sminthurus, I established that Sminthurus-Spatulosminthurus is a monophyletic group with Allacma as sister group. In the present paper, dealing with the genus Sminthurus, I will redescribe three species and describe four new species from northeastern Spain and southwestern France.

Sminthurus includes about forty species (Betsch, 1980). Betsch \& Betsch-Pinot (1984) pointed out that the digited ornamentation on the male genital papilla is an autapomorphy of Sminthurus. In comparison with Allacma and Spatulosminthurus, the heterochaetosis of the seta $\mathrm{a}+1$ on the 2 nd antennal segment - modified into a small and slender seta on a large base - is also an evolved character peculiar to Sminthurus. Note that the setae $\mathrm{i} 0, \mathrm{i}+1$, and $\mathrm{i}+2$ of the 2nd antennal segment are small and slender 
on a large base in the three genera. The special shape of these three setae was held (Nayrolles, 1994) to be an autapomorphy of the monophyletic group Allacma-Spatulosminthurus - Sminthurus. The same morphology shown by seta $a+1$ can be seen as the further step of a single evolutionary trend (morphocline).

The presence of $(\mathrm{TI} 2,3) \mathrm{Vp}$ is a particular character. All the genera of Sminthuridae I observed lack (TI2,3)Vp except for Sminthurus. Therefore, the presence of (TI2,3) Vp in Sminthurus appears as evolved for the family Sminthuridae. As a rule, the most repetitive organizations are regarded as the putative primitive states in zoology as well as in botany, e.g., the homonomous segmentation in annelids (primitive) vs. the heteronomous segmentation in arthropods (evolved). This idea involves that five whorls saturated with setae in all tibiotarsi should be the primitive scheme for the primary tibiotarsal chaetotaxy in Symphypleona. Hence, one can assume that the presence of (TI2,3) Vp is originally primitive in Symphypleona. Thus, the absence of (TI2,3) Vp in Sminthuridae appears as an evolved character, and the presence of (TI2,3) Vp in Sminthurus as a reversion.

The bibliography is cluttered with many varieties of species of Sminthurus defined only on color. The color pattern generally shows a large range of variation within a species. Therefore, any attempt to settle the confusion by considerations on coloring is doomed to failure (except when the color pattern is fixed and very characteristic, but this case is rare). Wallace (1973) used several characters, but according to Ellis (1974: 137) "the set of characters that are available shows a very large overlap". Therefore, Ellis assessed that Wallace's conclusion was fruitless; I have the same opinion.

The problem of the distinction between species can be solved by using chaetotaxy. In this way, Ellis (1976) was able to separate $S$. nigromaculatus (a doubtful taxon until then) from $S$. viridis (S. nigromaculatus has a supplementary secondary seta on the apical subcoxa of the hindlegs). My previous studies and this one emphasize the use of chaetotaxy. Moreover, I assert that the observation of the chaetotaxy in juveniles should be required as well, and I will show that the main differences among the Sminthurus species lie in the 3rd instar.

One could suppose that experiments would be required to define juvenile instars. In principle, rearing isolated specimens and observing their molts should be the best method. Nevertheless, I stated that: "En pratique la définition des stades juvéniles d'une espèce peut se faire à partir de populations capturées dans la nature et conservées en alcool. En effet les observations menées sur la chétotaxie de certaines régions du corps concordent entre elles et permettent pour tous les juvéniles examinés de former divers ensembles cohérents constituant les différents stades immatures" (Nayrolles, 1989: 232). All Sminthuridae I have studied have four juvenile instars. One can easily separate instars of Sminthurus using sexual characters (adults vs. juveniles) and chaetotaxy, e.g., no secondary seta on legs in 2nd instar, femoral oval organ appears in 4th instar, etc. (see also ibid.: 237, Table II).

On the one hand, if we consider only the species liable to be really good species, and on the other hand, if we remove the species falling in Spatulosminthurus and Allacma (Betsch \& Betsch-Pinot, 1984) from the bibliography (Stach, 1956; Gisin, 1960; and Ellis, 1976) we can record five species of Sminthurus in Europe: S. viridis (Linnaeus, 1758), S. nigromaculatus Tullberg, 1871, S. multipunctatus Schäffer, 1896, S. maculatus Tömösvary, 1883, and S. wahlgreni Stach, 1919. S. punctatus Lucas, 1846 was described from Algeria, but was never recorded in Europe.

$S$. maculatus and $S$. wahlgreni occur in eastern or central Europe and I did not collect them. S. maculatus seems very close to $S$. viridis, since only the color pattern separates them in the keys to species by Stach (1956) and Gisin (1960). By its very special color marking, $S$. maculatus is distinguishable from all other species (including the new species described in this paper). S. wahlgreni shows some characters different from the other European species: empodial appendage untoothed and without filament, and mucro without seta. I collected many specimens of $S$. viridis, $S$. nigromaculatus, and $S$. multipunctatus in France and Spain. The characters available for distinguishing these species were: the claw with a tunica in viridis and nigromaculatus vs. without in multipunctatus, and a supplementary 
secondary seta on apical subcoxa of hindlegs present in nigromaculatus and multipunctatus vs. absent in viridis (Ellis, 1976).

Snider (1969) described the setae on abdomen V and proposed a nomenclature. He observed that the most dorsal seta, named $\mathrm{P}$ in his nomenclature, was ciliated in both species he described as new: Sminthurus butcheri Snider, 1969, and Sminthurus spinulosus Snider, 1969. Snider (1985) also showed that the $\mathbf{P}$ seta could be used to distinguish some related North American species of Sminthurus: this seta is ciliated in S. butcheri, S. fitchi Folsom, 1896, S. packardi Folsom, 1896, and smooth in $S$. bivittatus Snider, 1985 . In the figures given by Snider $(1981,1982)$, the $P$ seta is smooth in S. carolinensis Snider, 1981, and ciliated in S. floridanus MacGillivray, 1893. Sminthurus anomalus Betsch, 1964, considered by Christiansen \& Bellinger (1981) as a synonym of Sminthurus eiseni Schött, 1891, was described with a pair of ciliated setae on the small abdomen (Betsch, 1964) which corresponds to the $P$ setae.

No ciliated setae on abdomen $\mathbf{V}$ have hitherto been mentioned in European or Asiatic Sminthurus, and I confirm this feature for the species I have studied. Nevertheless, I observed that some species have two setae in the dorsal area of the trichobothrium D, dn and $\mathbf{P}$ in Snider's nomenclature (Fig. 25), whereas others have only the dn seta. Presence vs. absence of the $P$ seta is a worthwhile character because it seems invariable within species and easy to observe. In one North American species, $S$. butcheri, the lacking seta is not $P$ but $\mathrm{dn}$ (Snider, 1969).

I recall the abbreviations which correspond neither to setal symbols nor to the legend of the chaetotaxic table; these were explained in my first paper (Nayrolles, 1993a):

$$
\begin{array}{ll}
\text { abd. } & =\text { abdomen } \\
\text { ad. } & =\text { adult } \\
\text { an. app. } & =\text { anal appendage } \\
\text { ant. } & =\text { antennal segment } \\
\text { ceph. diag. } & =\text { cephalic diagonal } \\
\text { juv. } & =\text { juvenile } \\
\text { oc } & =\text { occurrence } \\
\text { ov. org. } & =\text { oval organ } \\
\text { st. } & =\text { instar }
\end{array}
$$

The material is deposited in the following collections: Laboratoire d'Ecologie des Invertébrés Terrestres, Université Paul Sabatier, Toulouse, France (LEITT); Muséum d'Histoire Naturelle de Genève, Switzerland (MHNG); Muséum National d'Histoire Naturelle, Paris, France (MNHN); Institute of Systematics and Population Biology (Zoölogisch Museum) Universiteit van Amsterdam, the Netherlands (ZMA).

\section{Taxonomic part}

Sminthurus viridis (Linnaeus, 1758) (Table I)

Material examined. $-S$. viridis was collected in many stations in southwestern France and northeastern Spain. Most of the specimens examined were collected at the following station: France, dép. Aveyron, district Bessuéjouls, near Caldegouse, alt. $400 \mathrm{~m}$; stream edge and damp meadow; collected with a net by Nayrolles (station AV10); 3-III-1987; many specimens collected and mounted.

Deposit of material. - All material in LEITT.

\section{Description. - Number of juv. st. $=4$.}

Size ad. male: $1.3-1.5 \mathrm{~mm}$; female: $1.6-2.4 \mathrm{~mm}$.

Color. Very variable. The best known form is fairly light green with yellow shades. Lightest specimens without mediodorsal black spots on upper anal flap but with two green spots darker than the background. Eyepatches black. Ant. I to III brown-purple, ant. IV with brown-rusty shades. Legs yellow-green. Furcula very light green or unpigmented. Specimens from Mediterranean populations are often more colored with a patchwork of white, black, sometimes pink, certain specimens being virtually devoid of green pigment. These specimens have the flanks quite dark, but ventral area not colored with black as in S. leucomelanus n. sp., a pair of dark laterodorsal stripes along the posterior part of great abd., and two black mediodorsal spots on upper anal flap. Coloring settles during development.

Great abd. Trichobothria: A, B, C appearing at 2nd st., in a very open inverted pattern. Dorsal setae: macrochaetae.

Antennae. Antennal ratios: in female, ant. I : II : III : IV = $1: 2.1: 3.1: 7.1$ and ant. : ceph. diag. = 1.7; in male, ant. I : II : III : IV $=1$ : $2.1: 3.3: 7.9$ and ant. $:$ ceph. diag. $=2.0$. Chaeto- 
Table I. Appendicular chaetotaxy of Sminthurus viridis.

\begin{tabular}{|c|c|c|c|c|c|c|c|c|c|c|c|c|}
\hline \multirow{4}{*}{ AP } & $\bar{\Delta}$ & \multicolumn{11}{|c|}{ - } \\
\hline & $\Pi$ & \multicolumn{11}{|c|}{-} \\
\hline & $\Delta$ & \multirow{2}{*}{\multicolumn{11}{|c|}{$\begin{array}{l}D: \text { io } T: \theta+1, a+1, i+1, p i+1, p e+1 \quad Q: p+1, i+2 \\
i 0, i+1, i+2, \text { and a+1 are small and slender setae on large base. }\end{array}$}} \\
\hline & & & & & & & & & & & & \\
\hline \multirow[t]{5}{*}{ AT } & $\Pi$ & \multicolumn{11}{|r|}{-} \\
\hline & \multirow[t]{4}{*}{$\Delta$} & & & Go & Gag & Ga & Gaj & $\mathbf{G i}$ & Gpi & $\mathbf{G}_{p}$ & Gpe & \multirow{4}{*}{$\begin{array}{l}\text { Other setae: Q: } p+2 \\
\text { Be, Bae, Ba, Bai, and Bp become macrochaetae during } \\
\text { development. }\end{array}$} \\
\hline & & & Setae -1 & & $T$ & a & $\mathbf{T}$ & $\mathbf{a}$ & $T$ & a & $T$ & \\
\hline & & & Setae 0 & & D & D & & D & D & & D & \\
\hline & & & Setae +1 & & $\mathbf{T}$ & $T$ & $T$ & & & $T$ & & \\
\hline \multirow[t]{6}{*}{ AQ } & str & \multicolumn{11}{|c|}{$\begin{array}{l}\text { B completely zoned. Section M euwhorled with } 14 \text { or } 15 \text { whorls. Right ouwhorlation. } \\
\text { Subsegmentation formula: } 1+14 / 15+1=(A)+(M 1,14 / 15)+(B) \text { with BA more or loss well individualized as a } \\
\text { subsegment. Right subsegmentation. }\end{array}$} \\
\hline & \multirow[t]{3}{*}{$\overline{\mathbf{A}}$} & $\bar{\Pi}$ & \multicolumn{10}{|c|}{ Alipi } \\
\hline & & H & \multicolumn{10}{|c|}{ Alleae, Allppe } \\
\hline & & $\Delta$ & \multicolumn{10}{|c|}{$\begin{array}{l}\text { Apical bulb: joined to the apex Subapical organ: medium-size } \\
\text { Allpe is a blunt microchaeta. }\end{array}$} \\
\hline & \multirow[t]{2}{*}{$\begin{array}{l}\mathbf{M} \\
\mathbf{Q} \\
\mathbf{B}\end{array}$} & $\mathrm{H}$ & \multicolumn{10}{|c|}{$\begin{array}{l}\text { Heas does not reach BA. For Hose }: m-9.3 ; \min =7 ; \max =11 \\
\text { For } H \text {. } \\
\text { For } h^{*}: m=10.0 ; \min =9.0 ; \max =11.0 \text {. }\end{array}$} \\
\hline & & $\mathbf{G}$ & \multicolumn{10}{|c|}{$\begin{array}{l}\text { Setae of BB: P: BBo, BBpe O: BBae, BBp / BA with } 2 \text { variable setae / n80\% }(B M)=9-15 \text { / n80\% }(B)=20 \text { - } \\
26 / \text { some cases of absence of } G \text { setae on } M / n 80 \%(G)=157-169 \text {. }\end{array}$} \\
\hline
\end{tabular}

\begin{tabular}{|c|c|c|c|c|}
\hline & pre & - & + & + \\
\hline & $\Delta$ & P:1 sota & P:1 sota & $T: 1$ ov. org. \\
\hline SA & $\Delta$ & - & P: 1 sota & P: 1 seta \\
\hline $\mathrm{CX}$ & $\bar{\Delta}$ & $\overline{P: i i}$ & P: ae, il, ms T: a, Oi1 & $P: a \theta, i 1, m s \quad T: a, 0 i 1$ \\
\hline \multirow[t]{2}{*}{ TR } & $\bar{\Pi}$ & - & - & \multirow{2}{*}{ T: a2, Oi1, Oi2 } \\
\hline & $\Delta$ & Q:pi & T: a2, Oi1, Oi2 Q: ae & \\
\hline \multirow[t]{2}{*}{ FE } & $\Pi$ & - & - & pe1 \\
\hline & $\Delta$ & T: pi2, p2, pe2, pe3 Q: a2, Op & T: a5, ai2, po2 Q: a2, ai5, po3, Op & $\begin{array}{l}\text { T: a5, ai2, pe2 Q: a2, ai5, pe3, Op } \\
\text { (Q)C: ai3 }(\propto c=0.7), \text { ai4 }(\propto c=0.8)\end{array}$ \\
\hline \multirow[t]{4}{*}{$\pi$} & $\mathbf{V}$ & - & - & - \\
\hline & $\mathrm{K}$ & - & - & - \\
\hline & FP & + & + & + \\
\hline & $\bar{\Delta}$ & $\begin{array}{l}\text { T: 4ai1, 4pi1, Vai, Vpi, FSa, FSpel, } \\
\text { O1pe, O2pe, O3po, O4pe } \\
\text { (T)Q: 3a (oc =0.8), 3p }(0 c=0.6) \text {, 4a1 } \\
\text { (oc = 0.5) } \\
\text { Q: 2ai, 3ae, 4ao1, 4p1, 4ai2, 4pi2, } \\
\text { FSeT, FSai, FSpi, O1ae }\end{array}$ & 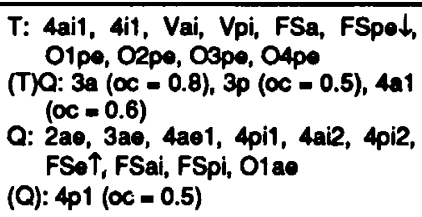 & 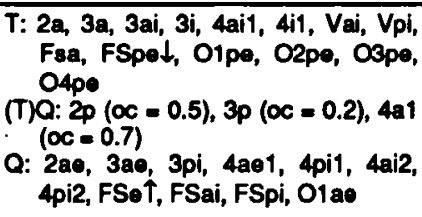 \\
\hline
\end{tabular}

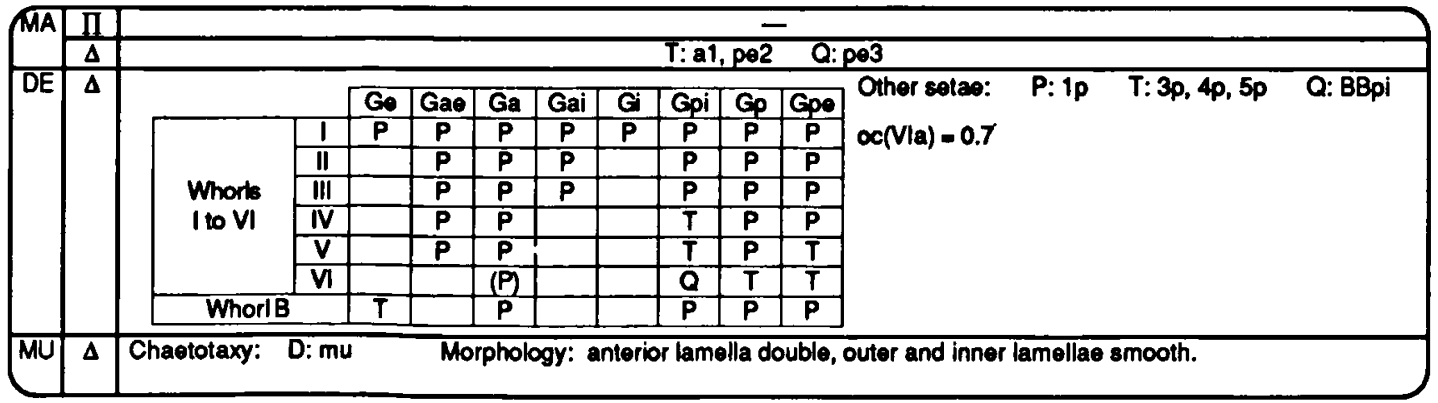


taxic variables: for $G: m=163.1 / s=4.23 /$ $\min =153 / \max =173$; for $I S h^{*}: m=0.65 / s=$ $0.026 / \min =0.59 / \max =0.70$; for $R S h: m=$ $0.54 / s=0.021 / \min =0.49 / \max =0.59$. Ant. II with 4 small and slender setae on large base, ant. III with 5 macrochaetae.

Head. Eyes: 8+8; eyepatch with 2 setae. Dorsal area of head with macrochaetae. One pair of postantennal setae fairly long. Labral formula: 6/5-5-4.

Legs. SA3 without secondary seta. Femur: cup present. Setae on inner side of tibiotarsi thickened, spine-like, and rough. Setae $2 \mathrm{a}, 3 \mathrm{a}$, and $4 \mathrm{a} 1$ on tibiotarsi are either present or variable in 3rd st. Claws of all legs with distinct tunica and pseudonychia. The tunica and pseudonychia grow during development. All legs with a tooth on inner crest of claw. Basal tooth of empodial outer lamella absent on forelegs but present on midlegs and hindlegs. All legs with a long empodial filament lengthening during development on hindlegs and to a lesser degree on midlegs.

Ventral tube. Sacs warty from 2 nd st. on. Chaetotaxy: apical flaps with one pair of primary setae, corpus without seta.

Retinaculum. At 1st st. rami tridentate, bidentate from 2nd st. on. Chaetotaxy: on anterior lobe one pair of setae appears at 3rd st., another pair at 4th.

Furcula. Cf. chaetotaxic table (Table I).

Small abd. Made up of abd. V + abd. VI. Trichobothrium: D present. Seta $P$ of abd. $V$ absent. Genital papilla of male medium-sized with a digited cuticular ornamentation and with about 50-60 setae. An. app. bent in sagittal plan. Ratio an. app. : mucro slightly smaller in populations from Spain (average $=0.46, \min =0.39, \max =$ 0.57 ) than in populations from France (average $=$ $0.54, \min =0.46, \max =0.61$ ).

\section{Sminthurus nigromaculatus Tullberg, 1871} (Table II)

Material examined. - France, dép. Landes, district Escource, Font de Saint-Antoine, alt. $70 \mathrm{~m}$; deforested area, moor with Calluna vulgaris (L.) and Pteridium aquilinum (L.); collected with a net by Nayrolles on unselected plants (station LA9b); 22-X-1987; many specimens; 39 juvs. and 4 ads. mounted.
Some other specimens from several northeastern Spanish and southwestern French stations mounted.

Deposit of material. - MHNG: station LA9b, 22-X-1987, 30 specimens in alcohol. MNHN: station LA9b, 22-X-1987, 30 specimens in alcohol. ZMA: station LA9b, 22-X-1987, 30 specimens in alcohol. LEITT: the rest of the material.

\section{Description. - Number of juv. st. $=4$.}

Size ad. male: $1.3-1.5 \mathrm{~mm}$; female: $1.4-2.0 \mathrm{~mm}$.

Color. Differences in color pattern within populations and between populations are rather strong, particularly for the extent of dark pigment. Two characteristics on ads.: small abd. of dark specimens with the two mediodorsal spots on upper anal flap fused, and posterior half of great abd. flecked with a pair of dorsal white stripes composed of ureic crystals. Pigment of lighter specimens very pale brown or sometimes greenish and limited to the posterior half of great abd. Pigment in darker specimens brown-purple. These specimens have the flanks marbled with many spots, a narrow mediodorsal stripe on anterior half of great abd., and often a brown patch between eyes. In some populations, body of darkest specimens (big females) entirely black-purple. Eyepatches black. In fairly pigmented specimens, antennae and legs light brown and spotted on basal segments. Furcula with some traces of pigment. As a rule, individuals with darker bodies have darker appendages. As in other species of Sminthurus, color changes during development.

Great abd. Trichobothria: A, B, C appearing at 2nd st., in a very open inverted pattern. Dorsal setae: macrochaetae.

Antennae. Antennal ratios: in female, ant. I : II : III : IV = $1: 2.1: 3.4: 7.9$ and ant. : ceph. diag. = 1.9; in male, ant. I : II : III : IV $=1$ : $2.3: 3.6: 8.5$ and ant. $:$ ceph. diag. $=2.2$. Chaetotaxic variables: for $G: m=160.1 / s=5.29 /$ $\min =147 / \max =167$; for $I S h^{*}: m=0.81 / s=$ $0.039 / \min =0.72 / \max =0.90$; for $R S h: m=$ $0.68 / s=0.028 / \min =0.62 / \max =0.74$. Ant. II with 4 small and slender setae on large base, ant. III with 5 macrochaetae.

Head. Eyes: $8+8$; eyepatch with 2 setae. Dorsal area of head with macrochaetae. One pair of long 
Table II. Appendicular chaetotaxy of Sminthurus nigromaculatus.

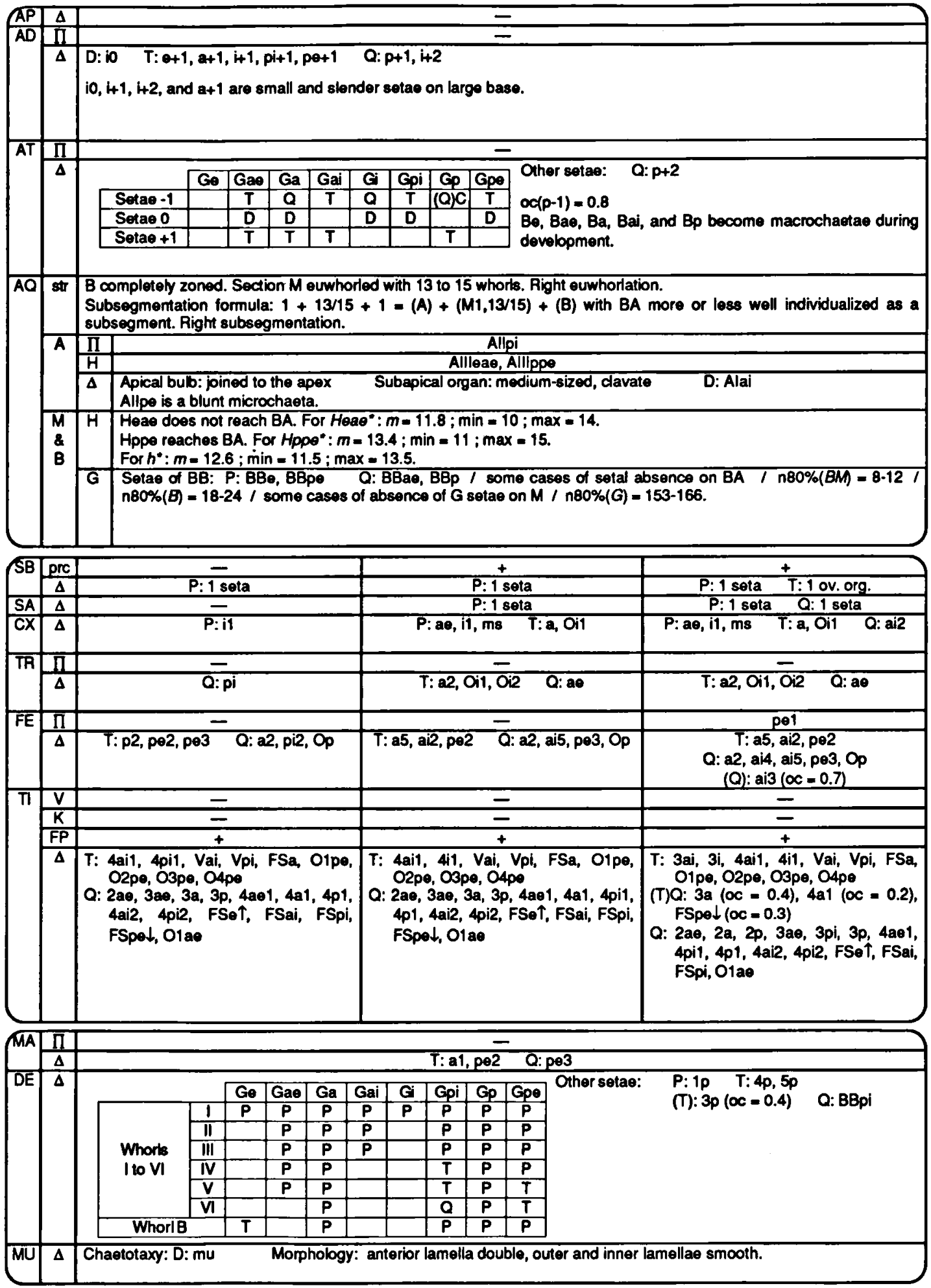


and tapered postantennal setae. Labral formula: 6/5-5-4.

Legs. SA3 with a secondary seta emerging at 4th st. Femur: cup present. Setae on inner side of tibiotarsi thickened, spine-like, and rough. Setae $2 a, 3 a$, and 4al on tibiotarsi are generally absent in 3rd st. Claws of all legs with distinct tunica and pseudonychia. The tunica and pseudonychia grow during development. All legs with a tooth on inner crest of claw. Basal tooth of empodial outer lamella absent on forelegs but present on mid- and hindlegs. All legs with a long empodial filament lengthening during development on hindlegs and to a lesser degree on midlegs.

Ventral tube. Sacs warty from 2 nd st. on. Chaetotaxy: apical flaps with one pair of primary setae, corpus with a pair from 4th st. on.

Retinaculum. At 1st st. rami tridentate, bidentate from 2nd st. on. Chaetotaxy: on anterior lobe one pair of setae appears at 3rd st., another pair at 4th.

Furcula. Cf. chaetotaxic table (Table II).

Small abd. Made up of abd. V + abd. VI. Trichobothrium: D present. Seta $\mathbf{P}$ of $\mathbf{a b d}$. $\mathbf{V}$ absent. Genital papilla of male medium-sized with a digited cuticular ornamentation and with 42-52 setae. An. app. fairly long and bent in sagittal plan. Ratio an. app. : mucro $=0.63(\mathrm{~min}=0.56$, $\max =0.71$ ).

\section{Sminthurus bourgeoisi n. sp.}

(Figs. 1-8, Table III)

Type material. - France, dép. Hérault, district Olargues, junction of roads D14 and D908, alt. $220 \mathrm{~m}$; garrigue with Erica cinerea L., Phillyrea angustifolia L., Lavandula stoechas L., Cistus salviaefolius L., and Quercus ilex L.; collected with a net by Nayrolles on unselected plants (station HT8); 20-III-1990. Syntypes: 136 specimens (mostly juvs.); 25 juvs., $4 \%$, and 5 o'o mounted.

Other material: Same station: $18-I V-1987 ; 4$ juvs. and 2 ९ , all mounted.

Deposit of material. - ZMA: 10 syntypes in alcohol. LEITT: the rest of the material.

Description. - Number of juv. st. $=4$.

Size ad. male: $1.3-1.4 \mathrm{~mm}$; female: $1.5-2.5 \mathrm{~mm}$.

Color. Similar to $S$. nigromaculatus, except that
S. bourgeoisi is not pigmented with purple shades, the brown tinge standing out.

Great abd. Trichobothria: A, B, C appearing at 2nd st., in a very open inverted pattern. Dorsal setae: macrochaetae.

Antennae. Antennal ratios: In female, ant. I : II $:$ III $:$ IV $=1: 2.1: 3.4: 7.9$ and ant. : ceph. diag. = 1.9; in male, ant. I : II : III : IV $=1$ : $2.2: 3.4: 8.1$ and ant. $:$ ceph. diag. $=2.0$. Chaetotaxic variables: for $G: m=154.8 / s=4.03 /$ $\min =145 / \max =163$; for $I S h^{*}: m=0.78 / s=$ $0.057 / \min =0.69 / \max =0.87$; for $R S h: m=$ $0.66 / s=0.040 / \min =0.60 / \max =0.73$. Ant. II with 4 small and slender setae on large base, ant. III with 5 macrochaetae. Seta BBp on ant. IV absent (compare Figs. 7 and 14).

Head. Eyes: 8+8; eyepatch with 2 setae. Dorsal area of head with macrochaetae. One pair of postantennal setae fairly long (Fig. 3). Labral formula: 6/5-5-4.

Legs (Figs. 4-6). SA3 without secondary seta. Femur: cup present. Setae (FE2,3)ai5 absent. Setae on inner side of tibiotarsi thickened, spine-like, and rough. Setae $2 \mathrm{a}, 3 \mathrm{a}$, and $4 \mathrm{al}$ on tibiotarsi generally absent in 3rd st. Claws of all legs with distinct tunica and pseudonychia. The tunica and pseudonychia grow during development. All legs with a tooth on inner crest of claw. Basal tooth of empodial outer lamella absent on forelegs but present on mid- and hindlegs. All legs with a long empodial filament lengthening during development on hindlegs and to a lesser degree on midlegs.

Ventral tube. Sacs warty from 2 nd st. on. Chaetotaxy: apical flaps with one pair of primary setae, corpus with a pair from 4th st. on.

Retinaculum. At 1st st. rami tridentate, bidentate from 2nd st. on. Chaetotaxy: on anterior lobe one pair of setae appears at 3rd st., another pair at 4th.

Furcula (Fig. 8). Note the absence of the dental seta $3 p$ (present in the other species of Sminthurus).

Small abd. Made up of abd. V + abd. VI. Trichobothrium: D present. Seta $\mathbf{P}$ of abd. $\mathbf{V}$ absent. Genital papilla of male medium-sized with a digited cuticular ornamentation and with 40-43 setae. An. app. long and bent in sagittal plan (Figs. $1-2)$. Ratio an. app. $:$ mucro $=0.68(\min =0.59$, $\max =0.75$ ). 
Etymology. - This species is dedicated to Mr. A. Bourgeois from the Laboratoire d'Ecobiologie des Arthropodes édaphiques, Université Paul Sabatier, Toulouse.

Diagnosis. - Some chaetotaxic characters single out bourgeoisi from the other species of Sminthurus that I have studied: absence of the setae (FE2,3)ai5, (DE)3p, and (AQ)BBp. Most of the secondary setae on tibiotarsi emerge at the 4 th instar, as in $S$. nigromaculatus.

Sminthurus bozoulensis n. sp.

(Figs. 9-12, Table IV)

Type material. - France, dép. Aveyron, district Montrozier, Causse Comtal, road of Gages, alt. $620 \mathrm{~m}$; grass on limestone with Bromus erectus Hudson, Koeleria valesiaca DC., Festuca gr. ovina, Coronilla minima L., Hippocrepis comosa L., Lotus corniculatus L., Anthyllis vulneraria L., Carduncellus mitissimus DC., Eryngium campestre L., Teucrium chamaedrys L., etc.; collected with a net by Nayrolles on unselected plants (station AV2a); 10-VII-1987. Syntypes: 26 ads.; $60^{\circ}$ and 2 ㅇ mounted.

Other material: Type station; 31-III-1987, 1 juv.; 17-IV-1987, 5 juvs., all mounted; 2-V-1987, 4 juvs.; 23-V-1987, 4 juvs., 1 mounted; 13-VI-1987, 16 ads.; 30-VII-1987, 17 juvs. and 2 ads., 7 juvs. mounted; 18-VIII-1987, 1 juv. and 33 ads.; 11-IX-1987, 62 juvs. and 3 ads., 4 juvs. mounted; 1-X-1987, 5 juvs. and 7 ads.; 18-X-1987, 9 ads.; 2-XI-1987, 1 ad.

Same location; doline with Molinia caerulea Moench, Avena pratensis L., Eryngium campestre L., Carduncellus mitissimus DC., Lathyrus pratensis L., Vicia peregrina L., and some specimens of Prunus spinosa L.; collected with a net by Nayrolles on unselected plants (station AV2b). Several collections in 1987, in all 70 specimens, 3 juvs. mounted.

Deposit of material. - MHNG: type station, 11-IX-1987, 10 juvs. in alcohol; 18-VIII-1987, 10 ads. in alcohol. MNHN: type station, 11-IX-1987, 10 juvs. in alcohol; 18-VIII-1987, 10 ads. in alcohol. ZMA: type station, 11-IX-1987, 10 juvs. in alcohol; 18-VIII-1987, 10 ads. in alcohol. LEITT: the rest of the material.

Description. - Number of juv. st. $=4$.

Size ad. male: $1.2-1.3 \mathrm{~mm}$; female: $1.3-1.9 \mathrm{~mm}$.

Color (Fig. 9). Uniformly greenish-yellow, more or less light. Small abd. with three spots in transversal line on upper anal flap. Eyepatches black and quite small. Antennae green-brown. Legs light green (lighter than body). Furcula white. This species shows a very characteristic color pattern with the three spots in transversal line on upper anal flap, so that even juvs. are readily distinguishable.

Great abd. Trichobothria: A, B, C appearing at 2nd st., in a very open inverted pattern. Dorsal setae: macrochaetae.

Antennae. Antennal ratios: in female, ant. I : II : III : IV = $1: 2.1: 3.1: 7.5$ and ant. : ceph. diag. = 1.8; in male, ant. I : II : III : IV $=1:$ $2.0: 3.2: 7.9$ and ant. $:$ ceph. diag. $=2.0$. Chaetotaxic variables: for $G: m=154.8 / s=4.35 /$ $\min =146 / \max =163$; for $I S h^{*}: m=0.77 / s=$ $0.037 / \min =0.71 / \max =0.87$; for $R S h: m=$ $0.64 / s=0.025 / \min =0.60 / \max =0.70$. Ant. II with 4 small and slender setae on large base, ant. III with 5 macrochaetae.

Head. Eyes: $8+8$; eyepatch with 2 setae. Dorsal area of head with macrochaetae. One pair of medium-sized postantennal setae (Fig. 12). Labral formula: 6/5-5-4.

Legs. SA3 with a secondary seta emerging at 4th st. Femur: cup present. Setae on inner side of tibiotarsi thickened, spine-like, and rough. Setae $2 a$,

Figs. 1-8. Sminthurus bourgeoisi n. sp. ad.: 1, an. app., ventral view; 2, an. app., lateral view; 3, postantennal seta; 4, basal segments of hindleg (from basal subcoxa to femur), anterior view, setae numbered on the femur correspond to the setal series Gai (i.e., ail, ai2, ai3, and ai4); 5, tibiotarsus and praetarsus of hindleg, anterior view; 6, schematic representation of hindtibiotarsus (from Fig. 5), setae of $\mathrm{Ge}$ and $\mathrm{Gi}$ drawn as ov. orgs., other setae are schematized as follows: a full symbol for a seta on reader's side (thus on anterior side), an empty symbol for a seta on opposite of reader's side, a circle for a primary seta, and a triangle for a secondary seta; setae belonging to a same whorl are linked together by a line which is continuous on the anterior side and discontinuous on the posterior side; 7 , basal part of ant. IV, anterior view, setae of BB are indicated with the letters of their generatrices (e.g., e for the seta BBe); 8, manubrium and dentes, posterior view; on the right, same schematic representation as in Fig. 6, except that reader's side is the posterior side.

Figs. 9-12. Sminthurus bozoulensis n. sp. ad.: 9, habitus female; 10, an. app., ventral view; 11, ventral tube, anterior view, arrows point to secondary setae on corpus; 12 , postantennal seta. 


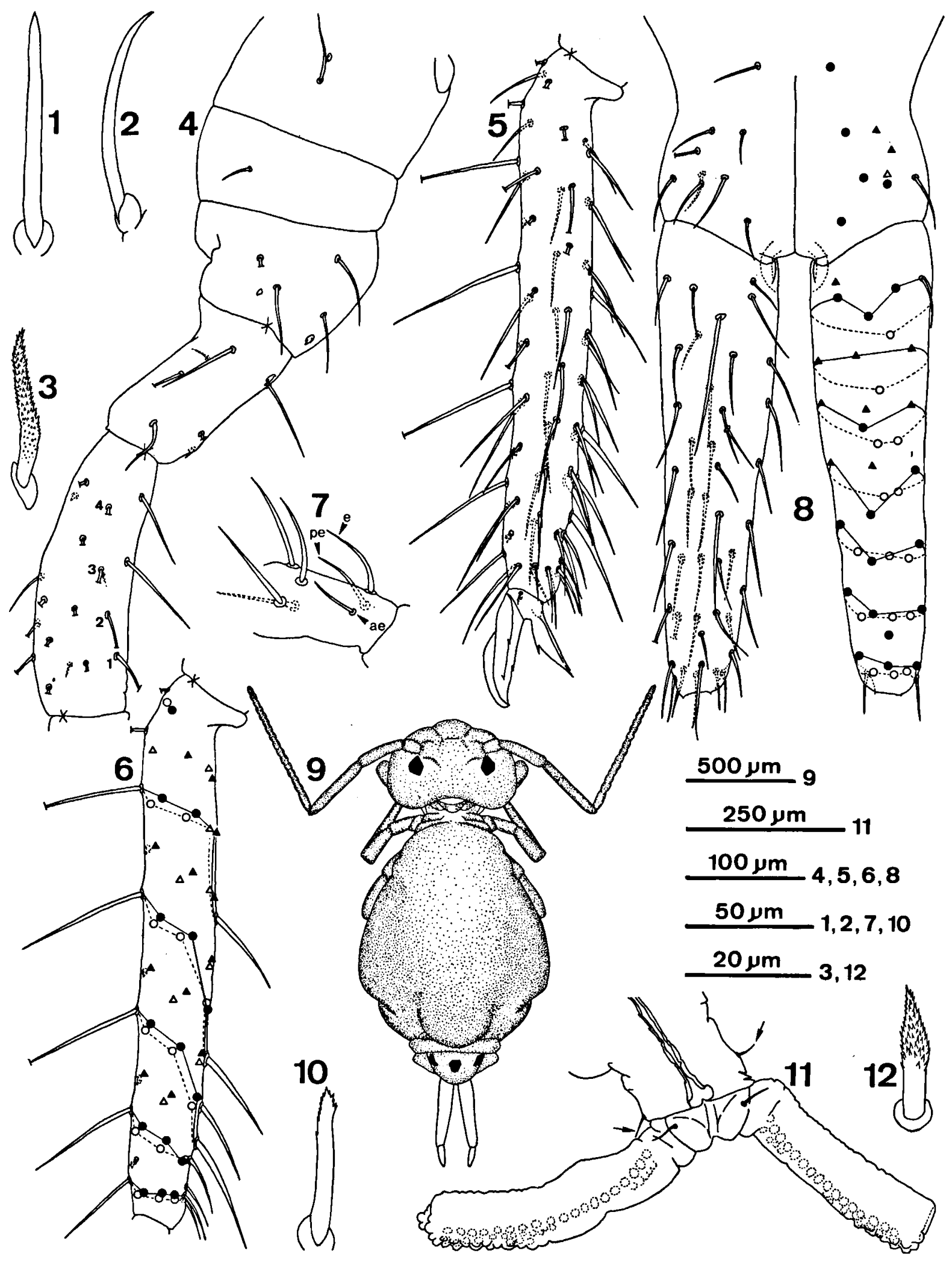


Table III. Appendicular chaetotaxy of Sminthurus bourgeoisi n. sp.

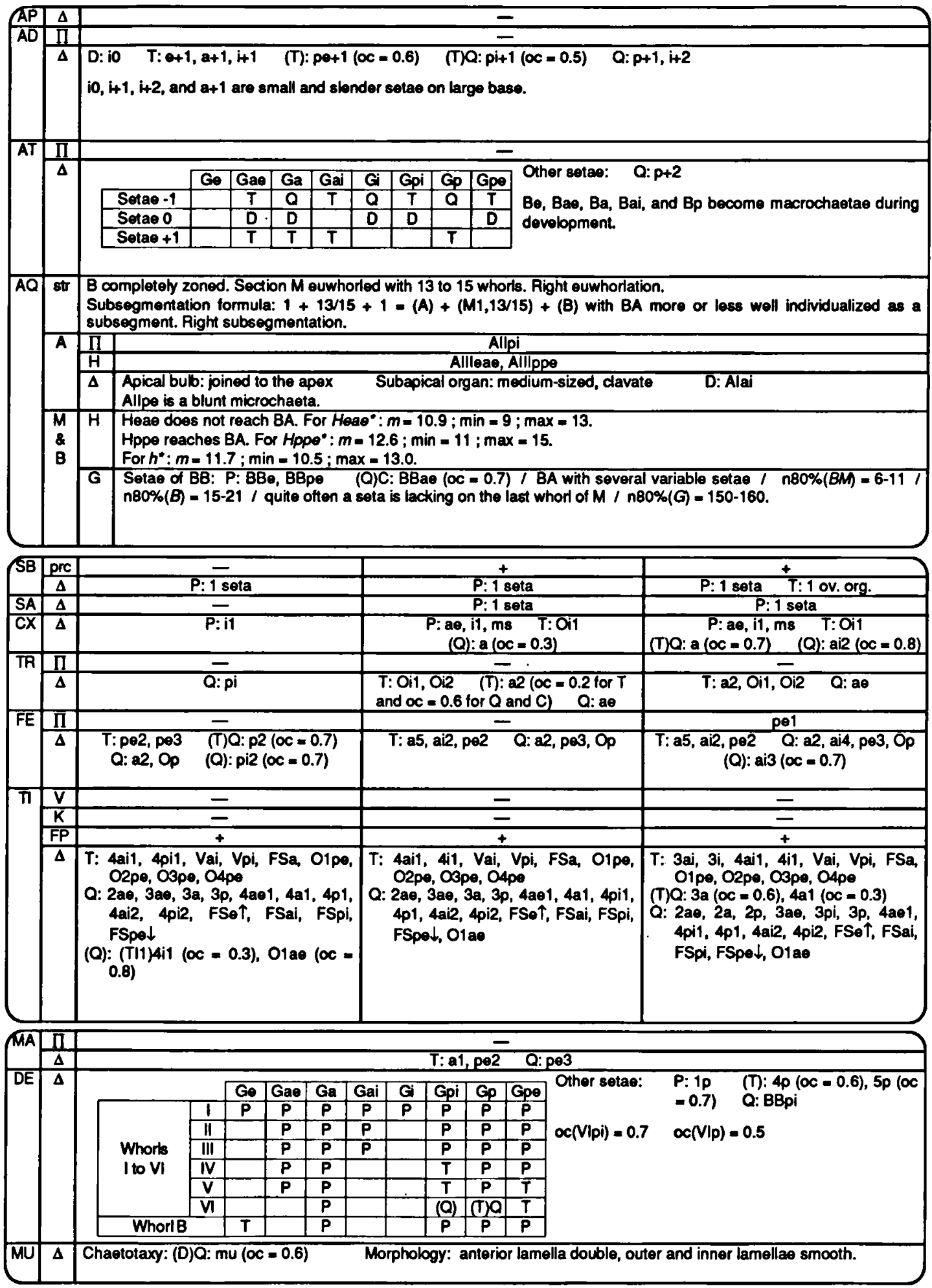


Table IV. Appendicular chaetotaxy of Sminthurus bozoulensis $\mathrm{n}$. sp.

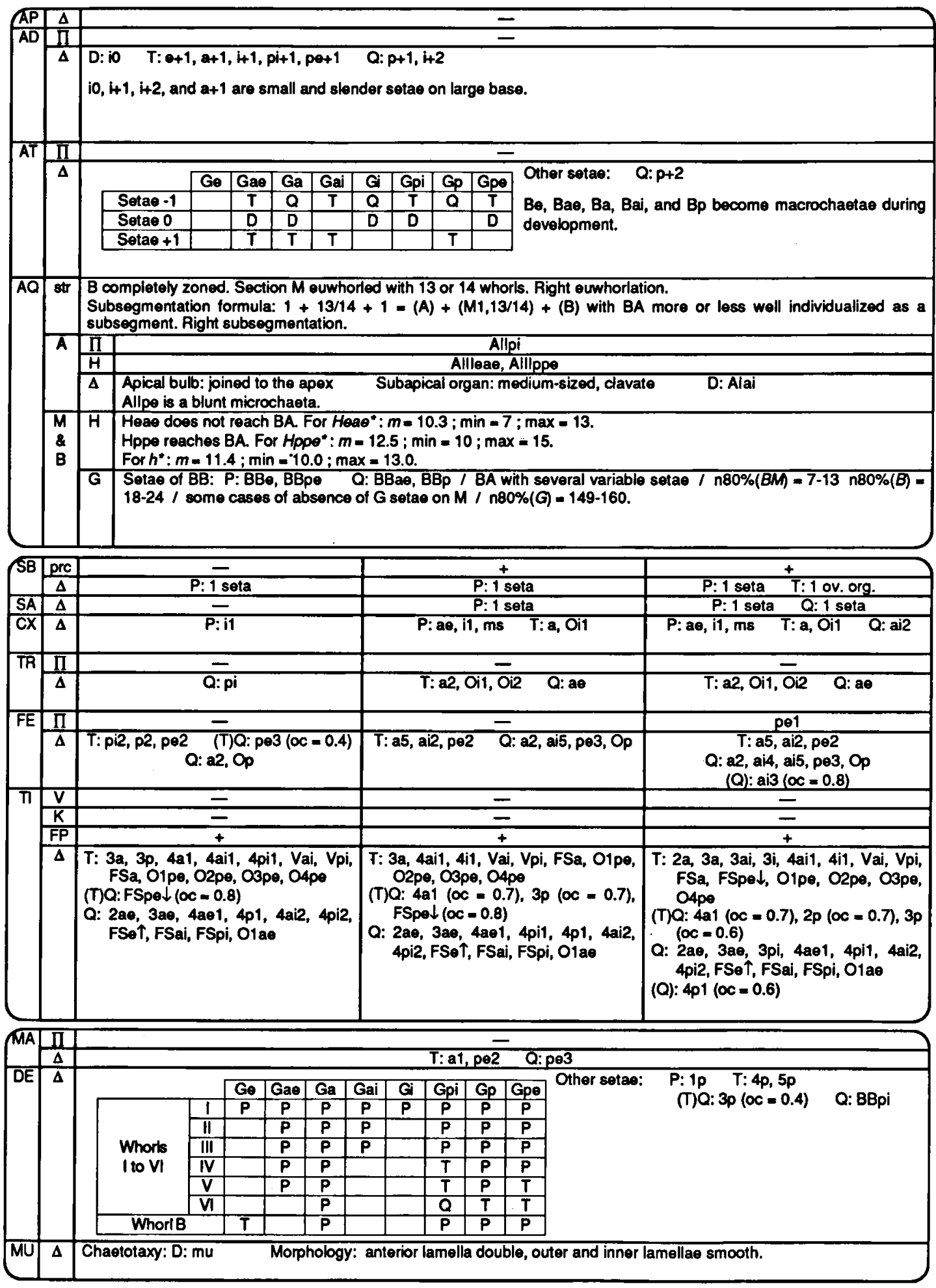


$3 a$, and $4 \mathrm{a} 1$ on tibiotarsi are either present or variable in 3rd st. Claws of all legs with distinct tunica and pseudonychia. The tunica and pseudonychia grow during development. All legs with a tooth on inner crest of claw. Basal tooth of empodial outer lamella absent on forelegs but present on mid- and hindlegs. All legs with a long empodial filament lengthening during development on hindlegs and to a lesser degree on midlegs.

Ventral tube (Fig. 11). Sacs warty from 2nd st. on. Chaetotaxy: apical flaps with one pair of primary setae, corpus with a pair from 4th st. on.

Retinaculum. At 1st st. rami tridentate, bidentate from 2nd st. on. Chaetotaxy: on anterior lobe one pair of setae appears at 3rd st., another pair at 4th.

Furcula. Cf. chaetotaxic table (Table IV).

Small abd. Made up of abd. V + abd. VI. Trichobothrium: D present. Seta $P$ of abd. V absent. Genital papilla of male medium-sized with a digited cuticular ornamentation and with 50-55 setae. An. app. (Fig. 10) very slightly bent and with small teeth at apex. Ratio an. app. : mucro $=0.48$ $(\min =0.45, \max =0.52)$.

Etymology. - Named after Bozouls (letter s is silent), a nice village in Causse Comtal (dép. Aveyron), where the species was abundantly present.

Diagnosis. - Two of the species studied have a tunica and a supplementary secondary seta on the apical subcoxa of the hindlegs: $S$. nigromaculatus and $S$. bozoulensis. The an. app. is longer in nigromaculatus (ratio an. app.: mucro $=0.63$ ) than in bozoulensis (an. app. : mucro $=0.48$ ). Most of the tibiotarsal secondary setae emerge at the 3rd st. in bozoulensis and at the 4th in nigromaculatus. The characteristic color pattern of bozoulensis makes the identification of this species very easy.

\section{Sminthurus leucomelanus $\mathrm{n}$. sp.}

(Figs. 13-16, Table V)

Type material. - France, dép. Pyrénées-Orientales, district Laroque-des-Albères, Pic de Neulos, alt. $1250 \mathrm{~m}$; moor with Calluna vulgaris (L.); collected with a net by Nayrolles (station
PO14b); 3-V-1990. Syntypes: 23 specimens; 10 juvs., 2 $\%$, and

2 ơo mounted.

Other material: Type station; 25-IV-1987, 6 juvs., 4 mounted.

France, dép. Pyrénées-Orientales, district Sorède, cart track between Sorède and Pic de Neulos, alt. $450 \mathrm{~m}$; grass under trees, Quercus ilex L., Cerasus avium (L.), Corylus avellana L., with Ficaria ranunculoides (L.), Mercurialis annua L., Cardamine hirsuta L., and Helleborus foetidus L.; collected with a net by Nayrolles on unselected plants of the herbaceous stratum (station PO12a); 25-IV-1987; 6 ads., 2 mounted.

Same location; edge of track with Quercus ilex L., Erica arborea L., Calluna vulgaris (L.), and Cytisus scoparius (Koch); collected with a net by Nayrolles on unselected plants (station PO12c); 25-IV-1987; 1 juv.

Spain; prov. Gerona, between Llançà and El Port de la Selva, about $3 \mathrm{~km}$ from Llança, alt. $50 \mathrm{~m}$; colonization of a burned area, grass-garrigue with Psoralea bituminosa L., Calycotome spinosa L., Andropogon hirtus L., and some Quercus suber L.; collected with a net by Nayrolles on unselected plants of the herbaceous stratum (station GE14a); 16-XII-1987; 16 specimens; 4 juvs., 1 \%, and 2 ơ mounted.

Spain, prov. Gerona, near Capmany; garrigue with Quercus suber L., Cistus monspeliensis L., Lavandula stoechas L., Genista scorpius DC., and Ulex parviflorus Pourret; collected with a net by Nayrolles on unselected plants (station GE25); 3-V-1990; 2 juvs. and $1 \&, 1$ juv. mounted.

Deposit of material. - ZMA: 4 syntypes ( $2 \% \bigcirc$ and 2 juvs.) in alcohol; station PO12a, 25-IV-1987, $1 \sigma^{\circ}$ and $1 \%$ in alcohol; station GE14a, 16-XIl-1987, 1 \& and 1 juv. in alcohol. LEITT: the rest of the material.

Description. - Number of juv. st. $=4$.

Size ad. male: $1.3-1.8 \mathrm{~mm}$; female: $1.5-2.3 \mathrm{~mm}$. Color (Fig. 16). The most pigmented ads. show very light (often white) patches juxtaposed with dark brown patches tinged with olive-green or mahogany. This color pattern looks like a chessboard. Lower area of flanks black. Some black spots forming a V-shaped pattern about halfway of great abd. (tip of " $V$ " as a very wide angle pointed backwards). Posterior area of great abd. with two streaks of dark flecks converging towards the tip of the "V". Small abd. with two mediodorsal dark spots on upper anal flap. Lower anal flap dark. Posteroventral area of head black. A pair of dark spots behind eyes. Frons with a cross-shaped pattern. Eyepatches black. Antennae and legs greenbrown. Basal segments of legs marbled with dark olive-green. Furcula with some black pigment. In addition to this very characteristic dark form, a lighter form was also found in the samples. In this 
lighter form, the great abd. shows the halfway Vshaped pattern as well as both lateroposterior dark stripes, but other dark patches are very faded or even indistinct, except for a narrow anterior mediodorsal stripe. There are specimens with pigmentation intermediate between the dark and light forms. The color pattern settles progressively throughout development. Juvs. are lighter with more greenish shades.

Great abd. Trichobothria: A, B, C appearing at 2nd st., in a very open inverted pattern. Dorsal setae: macrochaetae.

Antennae. Antennal ratios: in female, ant. I : II : III : IV = $1: 2.2: 3.3: 7.4$ and ant. : ceph. diag. = 1.8; in male, ant. I : II : III : IV $=1$ : $2.1: 3.3: 8.1$ and ant. $:$ ceph. diag. $=2.0$. Chaetotaxic variables: for $G: m=169.3 / s=5.16 /$ $\min =160 / \max =180 ;$ for $I S h^{*}: m=0.68 / s=$ $0.032 / \min =0.62 / \max =0.76$; for $R S h: m=$ $0.58 / s=0.025 / \min =0.52 / \max =0.64$. Ant. II with 4 small and slender setae on large base, ant. III with 5 macrochaetae. Seta BBp present on ant. IV (Fig. 14).

Head. Eyes: $8+8$; eyepatch with 2 setae. Dorsal area of head with macrochaetae. One pair of postantennal setae fairly long. Labral formula: 6/5-5-4.

Legs. SA3 without secondary seta. Femur: cup present. Setae on inner side of tibiotarsi thickened, spine-like, and rough. Setae $2 \mathrm{a}, 3 \mathrm{a}$, and $4 \mathrm{al}$ on tibiotarsi are either present or variable in 3rd st. Claws (Fig. 15) of all legs with a very tiny tunica and distinct pseudonychia. Pseudonychia grow during development. All legs with a tooth on inner crest of claw. Basal tooth of empodial outer lamella absent on forelegs but present on mid- and hindlegs. All legs with a long empodial filament lengthening during development on hindlegs and to a lesser degree on midlegs.

Ventral tube. Sacs warty from 2 nd st. on. Chaetotaxy: apical flaps with one pair of primary setae, corpus with a pair from 4th st. on.

Retinaculum. At 1st st. rami tridentate, bidentate from 2nd st. on. Chaetotaxy: on anterior lobe one pair of setae appears at 3rd st., another pair at 4th.

Furcula (Fig. 13). Cf. chaetotaxic table (Table V).

Small abd. Made up of abd. V + abd. VI. Trichobothrium: D present. Seta $\mathbf{P}$ of abd. V present. Genital papilla of male medium-sized with a

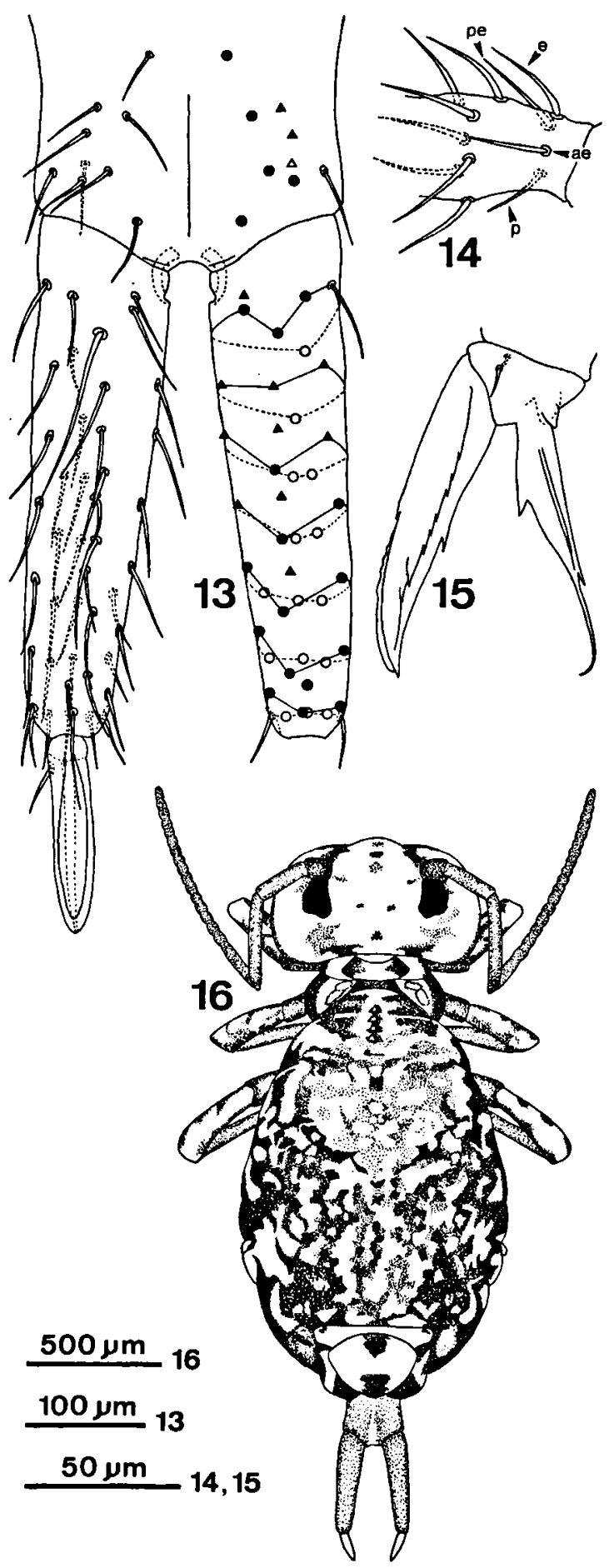

Figs. 13-16. Sminthurus leucomelanus n. sp. ad.: 13, furcula, posterior view; on the right, same schematic representation as in Fig. 8; 14, basal area of ant. IV, anterior view, as in Fig. 7 setae of BB are indicated with the letters of their generatrices; 15 , hindpraetarsus, anterior view; 16 , habitus female. 
Table V. Appendicular chaetotaxy of Sminthurus leucomelanus $\mathbf{n}$. sp.

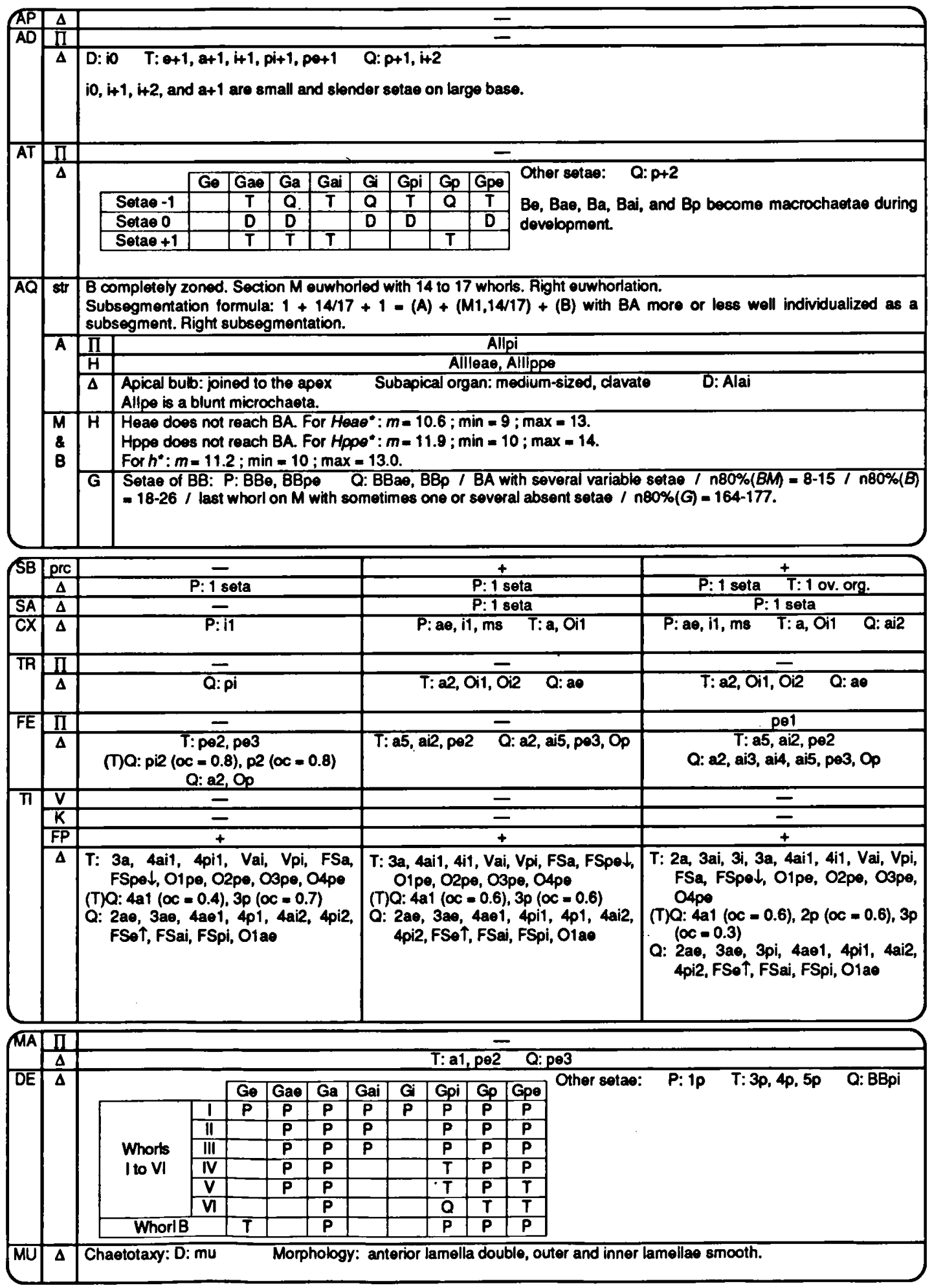


digited cuticular ornamentation and with about 60-70 setae. An. app. medium-sized and bent in sagittal plan. Ratio an. app. : mucro $=0.51$ $(\min =0.50, \max =0.53)$.

Etymology. - The name leucomelanus is derived from the Greek leucos (= white) and melas (= black), referring to the color of this species.

Diagnosis. - S. leucomelanus is close to $S$. viridis. In particular, the ontogeny of the tibiotarsal chaetotaxy is very similar in both species. However, the seta $P$ of abd. $V$ present in $S$. leucomelanus and absent in $S$. viridis permits to readily distinguish both species. Other discriminating characters of $S$. leucomelanus are the reduced tunica and a pair of secondary setae on the corpus of the ventral tube; the color pattern of ad. is also characteristic.

\section{Sminthurus multipunctatus Schäffer, 1896} (Fig. 17, Table VI)

Material examined. - France, dép. Aveyron, district Montrozier, Causse Comtal, road of Gages, alt. $620 \mathrm{~m}$; grass on limestone with Bromus erectus Hudson, Koeleria valesiaca DC., Festuca gr. ovina, Coronilla minima L., Hippocrepis comosa L., Lotus corniculatus L., Anthyllis vulneraria L., Carduncellus mitissimus DC., Eryngium campestre L., Teucrium chamaedrys L., etc.; collected with a net by Nayrolles on unselected plants (station AV2a). Several collections from September to November 1987; many specimens; 30 juvs. and 10 ads. mounted.

Same location; doline with Molinia caerulea Moench, Avena pratensis L., Eryngium campestre L., Carduncellus mitissimus DC., Lathyrus pratensis L., Vicia peregrina L., and some specimens of Prunus spinosa L.; collected with a net by Nayrolles on unselected plants (station AV2b). Several collections from September to November 1987; many specimens; 6 juvs. and 3 ads. mounted.

Spain, prov. Gerona, Sierra de Montseny, between Sant Marçal and Viladrau, about 3-4 km from Sant Marçal, alt. $1100 \mathrm{~m}$; short grass grazed by sheep; collected with a net by Nayrolles (station GE19a); 17-XII-1987; 23 specimens; 3 juvs. and 2 0० mounted.

Deposit of material. - MHNG: station AV2b, 28-XII-1987, 10 specimens in alcohol. MNHN: station AV2b, 28-XII-1987, 10 specimens in alcohol. ZMA: station AV2b, 28-XII-1987, 10 specimens in alcohol. LEITT: the rest of the material.

Description. - Number of juv. st. $=4$.
Size ad. male: $1.3-1.5 \mathrm{~mm}$; female: $1.7-2.3 \mathrm{~mm}$. Color (Fig. 17). Background rusty. Black pigment widely distributed on great abd.: in ventral area of flanks, in a pair of very irregular lateroposterior stripes, in a mediodorsal stripe, and in many flecks. Anterior area of great abd. marked with transversal streaks. Setal sockets dark. Posterior part of head and clypeolabral area black. A pair of black patches behind eyes. Frons more or less pigmented with dark. Eyepatches black. Antennae greenish-brown. Legs with rusty shades laid down in streaks on basal segments. Furcula slightly pigmented. In 1st st., background pale yellow with green patches fitting with dark flecks of ad. The color pattern settles progressively throughout development.

Great abd. Trichobothria: A, B, C appearing at 2nd st., in a very open inverted pattern. Dorsal setae: macrochaetae.

Antennae. Antennal ratios: in female, ant. I : II : III : IV = $1: 2.1: 3.1: 7.4$ and ant. : ceph. diag. = 1.9; in male, ant. I : II : III : IV $=1$ : $2.1: 3.2: 8.0$ and ant. $:$ ceph. diag. $=2.1$. Chaetotaxic variables: for $G: m=167.2 / s=4.11 /$ $\min =160 / \max =178$; for $I S h^{*}: m=0.68 / s=$ $0.032 / \min =0.63 / \max =0.75$; for $R S h: m=$ $0.57 / s=0.025 / \min =0.52 / \max =0.63$. Ant. II with 4 small and slender setae on large base, ant. III with 5 macrochaetae.

Head. Eyes: 8+8; eyepatch with 2 setae. Dorsal area of head with macrochaetae. One pair of medium-sized postantennal setae. Labral formula: 6/5-5-4.

Legs. SA3 with a secondary seta emerging at 4th st. Femur: cup present. Setae on inner side of tibiotarsi thickened, spine-like, and rough. Setae $2 a, 3 a$, and $4 \mathrm{a} 1$ on tibiotarsi appear at 3rd st. Claws of all legs without tunica but with distinct pseudonychia. Pseudonychia grow during development. All legs with a tooth on inner crest of claw. Basal tooth of empodial outer lamella absent on forelegs but present on mid- and hindlegs. All legs with a long empodial filament lengthening during development on hindlegs and to a lesser degree on midlegs.

Ventral tube. Sacs warty from 2nd st. on. Chaetotaxy: apical flaps with one pair of primary setae, corpus without seta. 
Table VI. Appendicular chaetotaxy of Sminthurus multipunctatus.

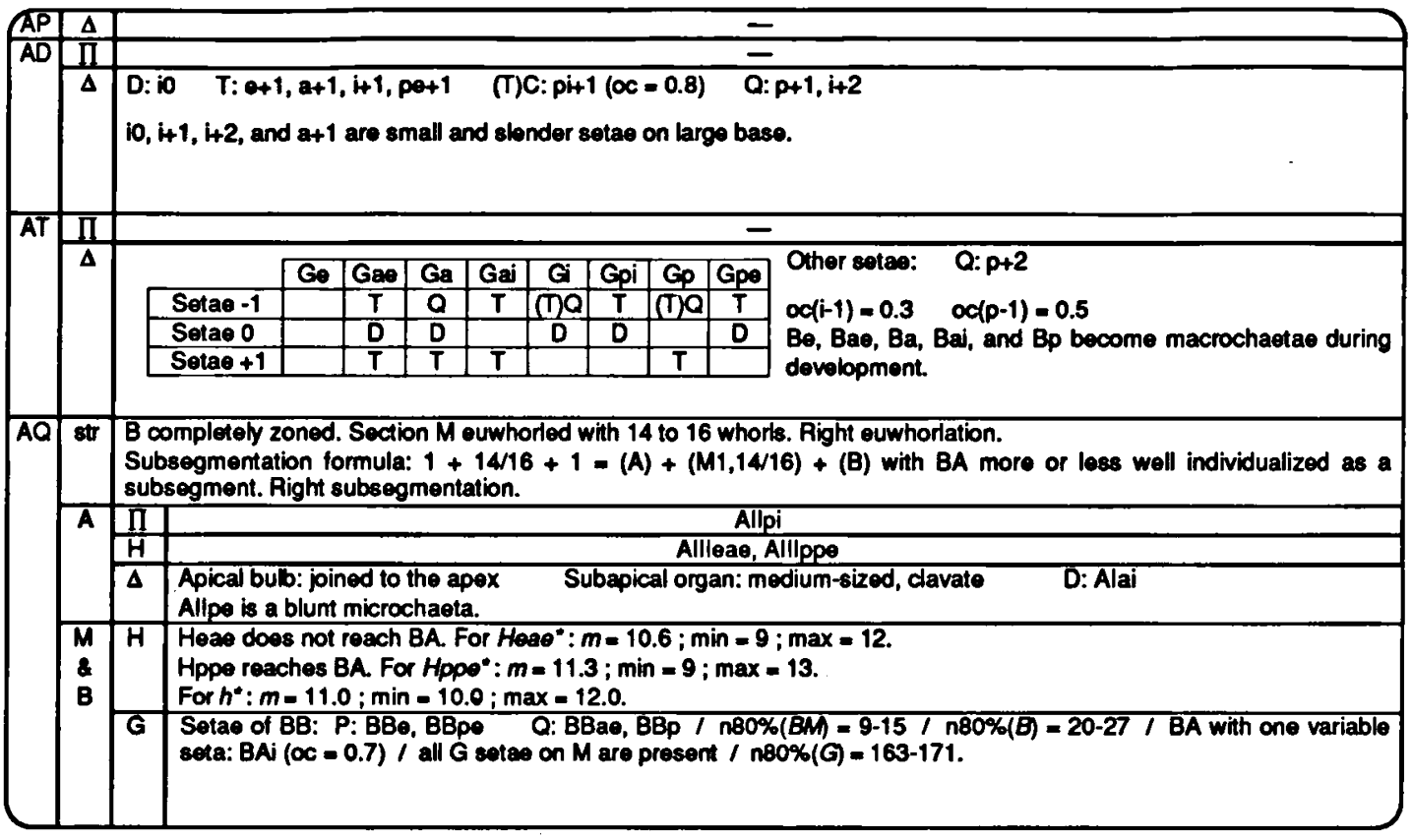

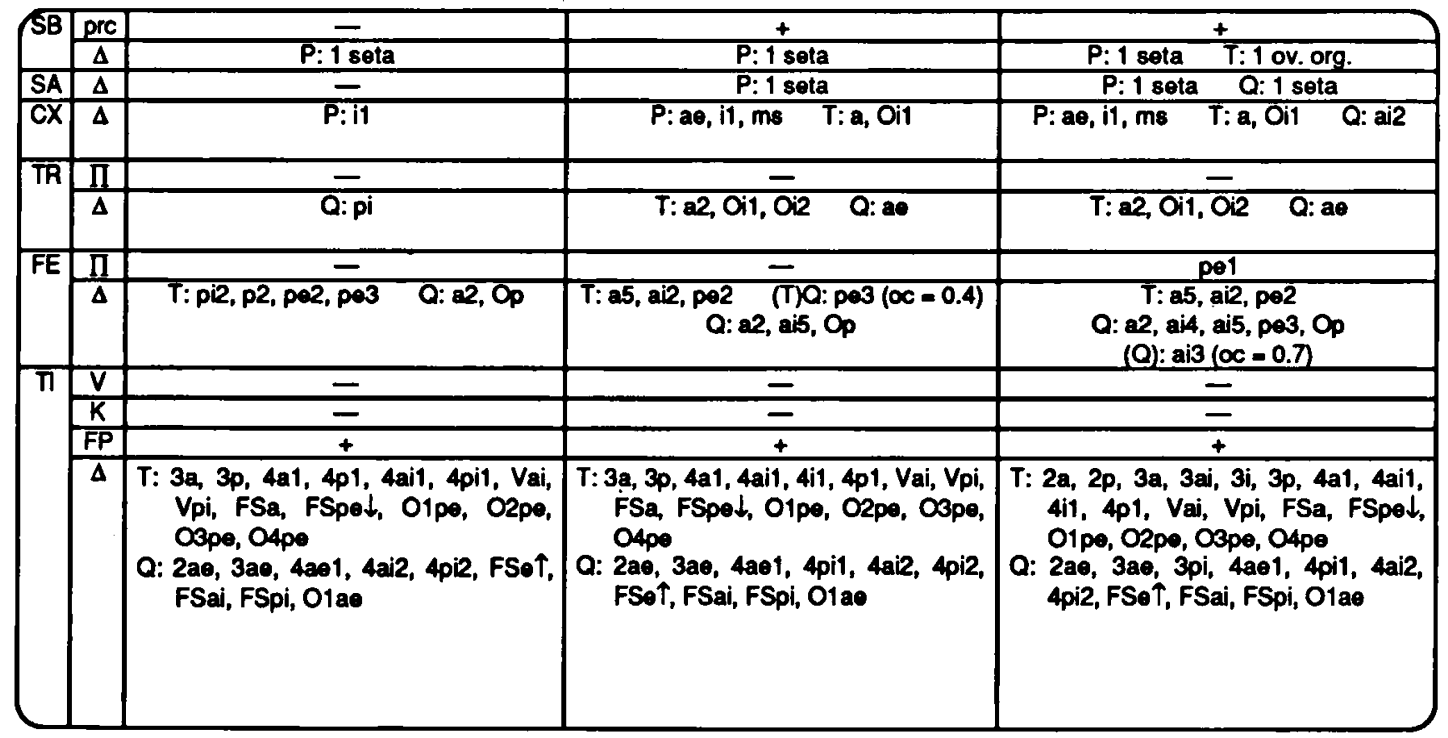

\begin{tabular}{|c|c|c|c|c|c|c|c|c|c|c|c|c|c|c|c|}
\hline \multirow[t]{2}{*}{ MA } & \multirow{2}{*}{$\frac{\Pi}{\Delta}$} & \multicolumn{14}{|c|}{-} \\
\hline & & & & & & & & & $T: \mathbf{a}$ & pe2 & & 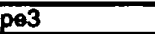 & & & \\
\hline \multirow[t]{8}{*}{$\overline{D E}$} & $\bar{\Delta}$ & & & $\mathrm{Ge}_{0}$ & Gae & Ga & Gai & $\mathbf{G}^{-}$ & Goi & $G_{0}$ & Gog & \multirow[t]{8}{*}{ Other setae: } & \multirow[t]{8}{*}{ P: 1p } & \multirow[t]{8}{*}{$T: 3 p, 4 p, 5 p$} & \multirow[t]{8}{*}{ Q: BBpi } \\
\hline & & \multirow{6}{*}{$\begin{array}{l}\text { Whorts } \\
\text { I to VI }\end{array}$} & $T$ & $\mathbf{P}$ & $\dot{p}$ & P & $P$ & $\vec{p}$ & wol & $\vec{p}$ & P & & & & \\
\hline & & & III & & $\bar{P}$ & $\mathbf{P}$ & $\dot{P}$ & & $\bar{P}$ & $P$ & P & & & & \\
\hline & & & III & & $\mathbf{P}$ & $\mathbf{P}$ & $\mathbf{P}$ & & $\mathbf{P}$ & $\mathbf{p}$ & $\mathbf{P}$ & & & & \\
\hline & & & IV & & $\mathbf{P}$ & $\mathbf{P}$ & & & $T$ & $\mathbf{P}$ & $\mathbf{P}$ & & & & \\
\hline & & & $\bar{v}$ & & $\bar{P}$ & $\mathbf{P}$ & & & $\bar{T}$ & $\mathbf{P}$ & $T$ & & & & \\
\hline & & & $\bar{v}$ & & & $\mathbf{P}$ & & & 0 & $T$ & $T$ & & & & \\
\hline & & \multicolumn{2}{|c|}{ WhorlB } & $T$ & & $\mathbf{P}$ & & & $\overline{\mathbf{P}}$ & $\vec{P}$ & $\mathbf{P}$ & & & & \\
\hline MU & $\Delta$ & $\begin{array}{l}\text { Chaetotaxy: (1 } \\
\text { and inner lam }\end{array}$ & & & & & & & & & & \multicolumn{4}{|c|}{ Morphology: anterior lamella double, outer } \\
\hline
\end{tabular}


Retinaculum. At 1st st. rami tridentate, bidentate from 2nd st. on. Chaetotaxy: on anterior lobe one pair of setae appears at 3rd st., another pair at 4th.

Furcula. Cf. chaetotaxic table (Table VI).

Small abd. Made up of abd. V + abd. VI. Trichobothrium: D present. Seta $P$ of abd. $V$ absent. Genital papilla of male medium-sized with a digited cuticular ornamentation, and with 42-49 setae in a French population (4 males observed) and 62-63 setae in a Spanish population ( 2 males observed). An. app. fairly short, bent in sagittal plan, and with minute teeth at apex. Ratio an. app. : mucro $=0.40(\min =0.37, \max =0.44)$.

Sminthurus hispanicus n. sp.

(Figs. 18-25, Table VII)

Type material. - Spain, prov. Huesca, Puerto de Monrepós, alt. $1260 \mathrm{~m}$; short grass grazed by sheep; collected with a net by Nayrolles (station HU24b); 30-X-1987. Syntypes: 122 specimens (mostly juvs.); 16 juvs. and $1 \%$ mounted.

Other material: Same location as type station; collected with a net on Genista horrida DC. by Nayrolles (station HU24c); 30-X-1987; 3 juvs., 1 mounted.

Spain, prov. Lérida, Sierra del Cadí, between Josa del Cadí and Gósol, alt. $1450 \mathrm{~m}$; short grass with Festuca sp., Juniperus communis L., and Buxus sempervirens L.; collected with a net by Nayrolles on graminae (station LE22); 15-IV-1988; 46 ads.

Spain, prov. Barcelona, near Olost, dry place on limestone with Brachypodium ramosum Roemer \& Schultes, Lavandula latifolia Villars, Thymus vulgaris L., Rosmarinus officinalis L., Quercus coccifera L., Dorycnium pentaphyllum Scopoli, Rubia peregrina L., Euphorbia nicaeensis Allioni, and Genista scorpius DC.; collected with a net by Nayrolles on unselected plants (station BA6); 27-IV-1987; 5 ads.; 1 \% mounted.

Spain, prov. Navarra, customs post between Ochagavia and Larrau pass, alt. $1360 \mathrm{~m}$; mountain pasture with Festuca sp. and Lycopodium selago L., some grassy areas free of snow; collected with a net by Nayrolles (station NA31); 16-II-1988; 22 ads.; $10^{\circ}$ and $1 \%$ mounted.

Spain, prov. Zaragoza, between Sierra de Luna and Castejón de Valdejasa, alt. about $600 \mathrm{~m}$; short grass grazed by sheep; collected with a net by Nayrolles (station SA8a); 31-X-1987; $1 \sigma^{\circ}$ and 24 juvs.; 1 o mounted.

Same location; grove of Pinus halepensis Miller, grass in undergrowth (mainly Agropyrum sp.); collected with a net by Nayrolles on unselected plants (station SA8b); 31-X-1987; 72 juvs., 6 mounted.

Spain, prov. Zaragoza, between Sádaba and Sos del Rey Católico, canal of Bárdenas, alt. $450 \mathrm{~m}$; dense grass with Brachypodium ramosum Roemer \& Schultes, Santolina chamaecyparissus L., Genista scorpius DC., Rosmarinus officinalis L., etc.; collected with a net by Nayrolles on unselected plants (station SA15); 16-II-1988; $10^{\circ}$ and 1 \% mounted.
Deposit of material. - MHNG: 10 syntypes (juvs.) in alcohol; station LE22, 15-IV-1988, 12 ads. in alcohol. MNHN: 10 syntypes (juvs.) in alcohol; station LE22, 15-IV-1988, 12 ads. in alcohol. ZMA: 10 syntypes (juvs.) in alcohol; station LE22, 15-IV-1988, 12 ads. in alcohol. LEITT: the rest of the material.

Description. - Number of juv. st. $=4$.

Size ad. male: $1.4-1.6 \mathrm{~mm}$; female: $1.7-2.3 \mathrm{~mm}$.

Color (Fig. 18). Background of ad. rusty ochre. Ventral area of great abd. very dark green, almost black. Dorsally, quadrangular patches more or less dark. Hind half of great abd. with a pair of laterodorsal streaks of very dark (often black) pigment. In mediodorsal area, several black patches, generally two or three anterior square patches with a sharp outline, some posterior patches more weakly outlined. Small abd. with two small mediodorsal spots on upper anal flap. Lower anal flaps dark in ventral area. Generally head with a pair of dark patches behind eyes. Frons and lateral sides of head more or less flecked. Dorsal setae of head with dark sockets. Eyepatches black. Antennae brown. Legs dark mottled on basal segments, tibiotarsi with light greenish-ochre. Furcula pigmented with purple. Juvs. are lighter and mottled with greenish tinge. The color pattern settles throughout development.

Great abd. Trichobothria: A, B, C appearing at 2nd st., in a very open inverted pattern. Dorsal setae: macrochaetae.

Antennae. Antennal ratios: in female, ant. I : II $:$ III $:$ IV $=1: 2.1: 3.1: 7.6$ and ant. : ceph. diag. = 1.8; in male, ant. I : II : III : IV $=1$ : $2.1: 3.1: 7.8$ and ant. $:$ ceph. diag. $=2.0$. Chaetotaxic variables: for $G: m=172.9 / s=6.48 /$ $\min =162 / \max =190$; for $I S h^{*}: m=0.71 / s=$ $0.046 / \min =0.62 / \max =0.81$; for $R S h: m=$ $0.59 / s=0.038 / \min =0.52 / \max =0.69$. Ant. II with 4 small and slender setae on large base, ant. III with 5 macrochaetae.

Head. Eyes: $8+8$; eyepatch with 2 setae. Dorsal area of head with macrochaetae. Postantennal setae (Fig. 19) fairly short. Labral formula: 6/5-5-4.

Legs (Figs. 20-22). SA3 with often a secondary seta emerging at 4th st. Femur: cup present. Setae on inner side of tibiotarsi thickened, spine-like, and rough. Setae $2 \mathrm{a}, 3 \mathrm{a}$, and $4 \mathrm{al}$ on tibiotarsi present in 3rd st. Claws of all legs without tunica but with 


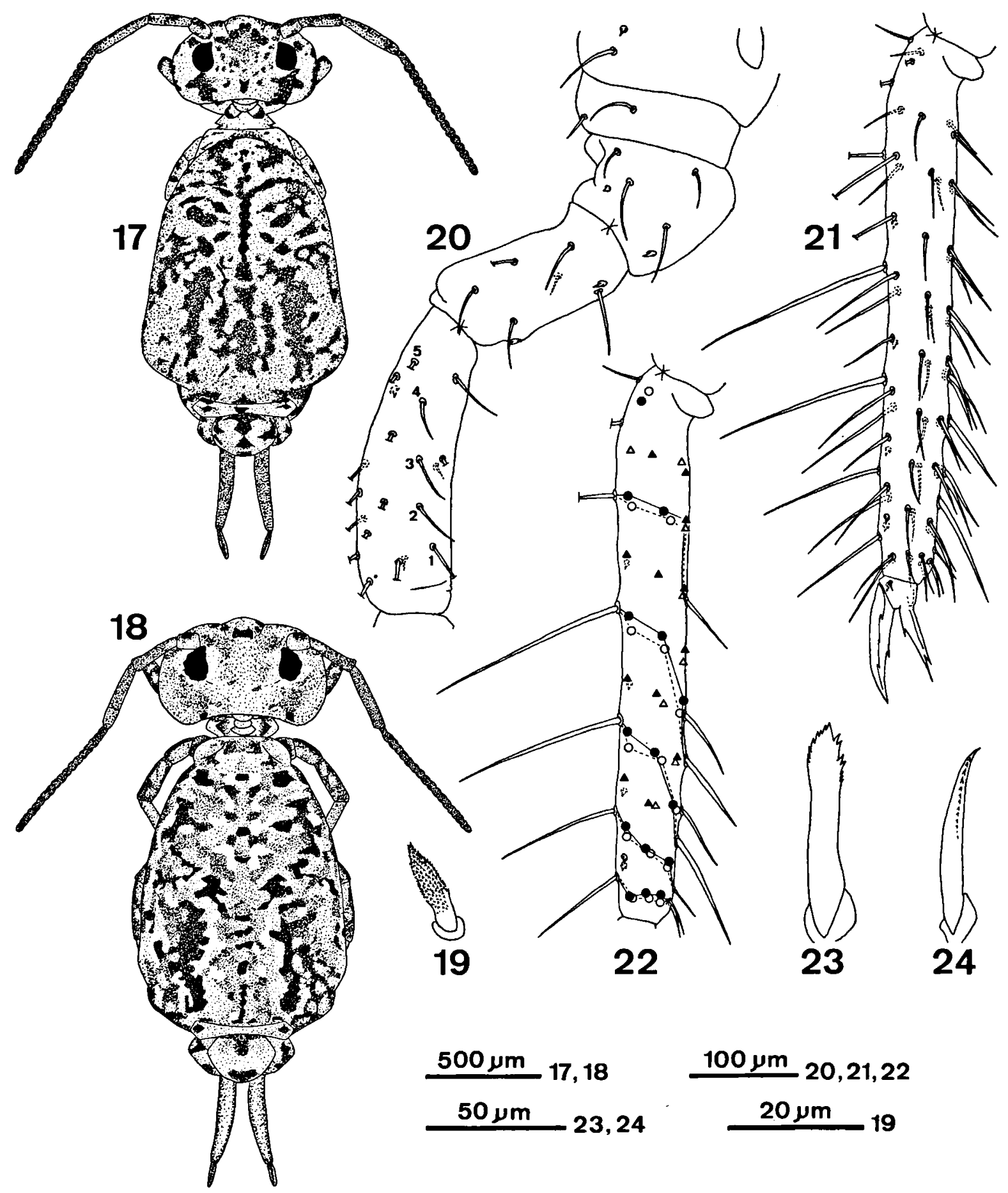

Fig. 17. Sminthurus multipunctatus, habitus female.

Figs. 18-24. Sminthurus hispanicus n. sp. ad.: 18, habitus female; 19, postantennal seta; 20, basal segments of hindleg (from basal subcoxa to femur), anterior view, setae numbered on the femur correspond to the setal series of Gai (i.e., ai1, ai2, ai3, ai4, and ai5); 21, tibiotarsus and praetarsus of hindleg, anterior view; 22, schematic representation of hindtibiotarsus (from Fig. 21), same legend as in Fig. 6; 23, an. app., ventral view; 24, an. app., lateral view. 
Table VII. Appendicular chaetotaxy of Sminthurus hispanicus n. sp.

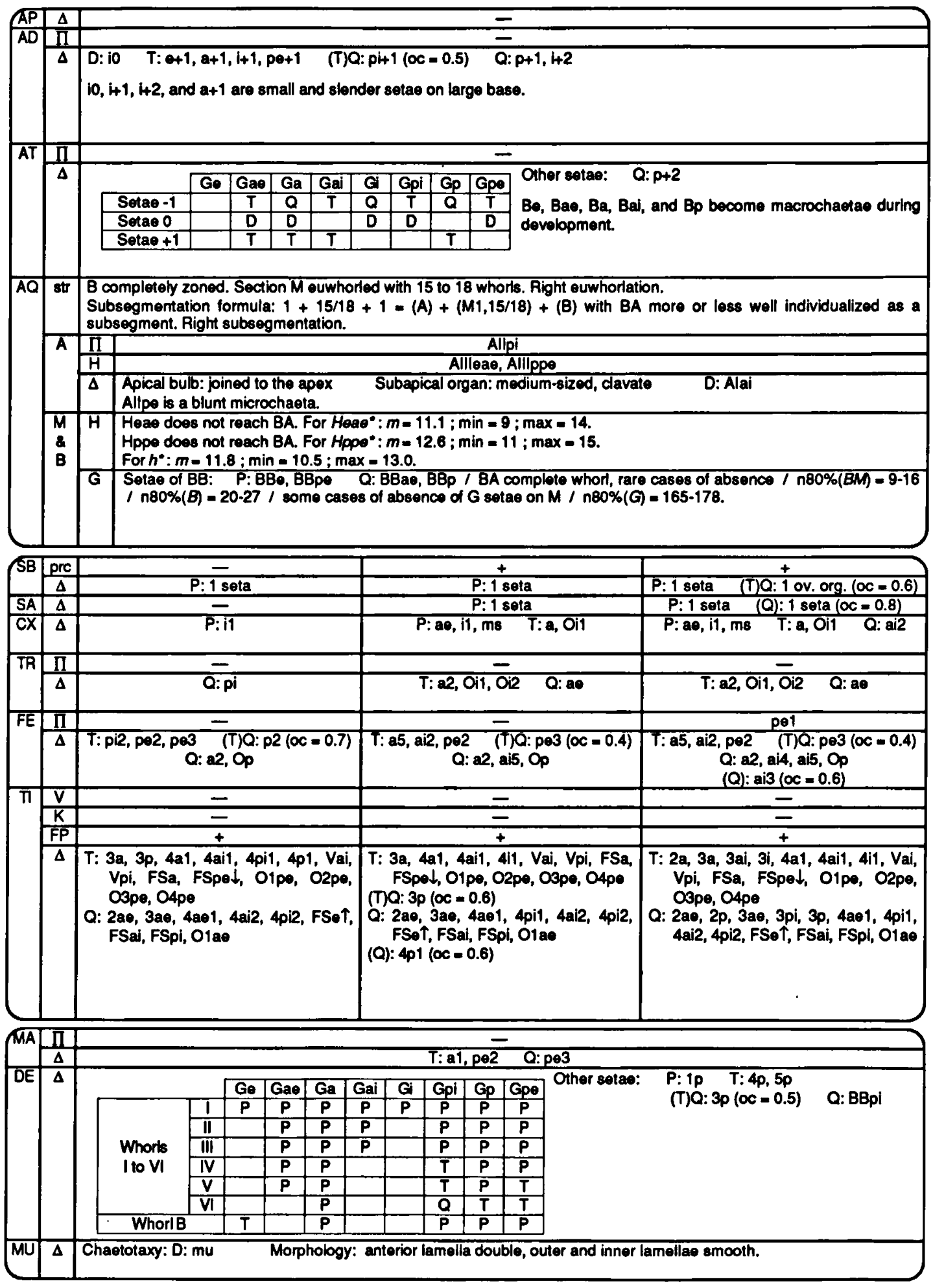




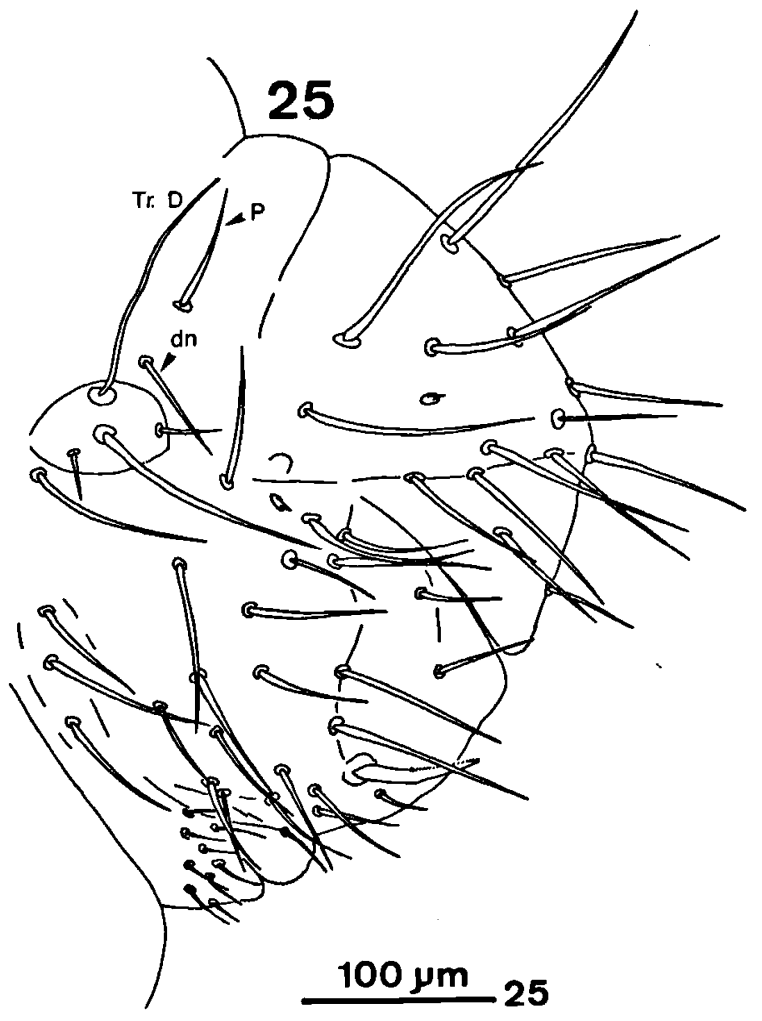

Fig. 25. Sminthurus hispanicus n. sp., female small abd., Tr. $D=$ trichobothrium $D, P$ and $d n$ are named in Snider's nomenclature.

distinct pseudonychia. Pseudonychia grow during development. All legs with a tooth on inner crest of claw. Basal tooth of empodial outer lamella absent on forelegs but present on mid- and hindlegs. All legs with a long empodial filament lengthening during development on hindlegs and to a lesser degree on midlegs.

Ventral tube. Sacs warty from 2 nd st. on. Chaetotaxy: apical flaps with one pair of primary setae, corpus without seta.

Retinaculum. At 1st st. rami tridentate, bidentate from 2nd st. on. Chaetotaxy: on anterior lobe one pair of setae appears at 3rd st., another pair at 4th.

Furcula. Cf. chaetotaxic table (Table VII).

Small abd. (Fig. 25). Made up of abd. V + abd. VI. Trichobothrium: D present. Seta $P$ of abd. V present. Genital papilla of male medium-sized with a digited cuticular ornamentation and with about 78 setae. An. app. (Figs. 23-24) fairly short and finely serrated on its lateral edges. Ratio an. app. : mucro $=0.43(\min =0.39, \max =0.49)$.

Etymology. - The name hispanicus refers to Spain where this species occurs in winter.

Diagnosis. - $S$. hispanicus lacks a tunica, as does $S$. multipunctatus. The presence of the seta $P$ of abd. $\mathrm{V}$ in $S$. hispanicus vs. its absence in $S$. multipunctatus makes the identification of both species very easy. The color pattern and the presence in S. multipunctatus vs. absence in S. hispanicus of (TI3)4p1 (compare Tables VI and VII, see also Table VIII) are also discriminating.

\section{Discussion}

Table VIII lists the differences between adults (differences are the same for preadults except for the length of an. app.). Several differences concern the instar of emergence of secondary setae (3rd or 4th st.). Chaetotaxy is very useful for confirming the specific status of sibling species, and I will show that its study on the 3rd instar is fruitful. Nevertheless, setal criteria may be difficult to apply, and easier characters should be proposed to distinguish species. Hence, I give here a key to European species of Sminthurus restricted to adults and making use of color pattern whenever it is characteristic. This key includes $S$. wahlgreni and $S$. maculatus which were not studied.

\section{Key to European species of Sminthurus}

1. Empodial appendage of all legs untoothed and without a filament, mucronal seta absent ............. wahlgreni

- Empodial appendage untoothed on forelegs and with a very distinct tooth on mid- and hindlegs, empodial filament present on all legs, mucronal seta present $\ldots \ldots \ldots \ldots 2$

2. Claw without a tunica, and an. app. short (less than half the

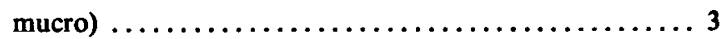

- Claw with a tunica, and in case the tunica is reduced (difficult to observe) an. app. is not short ............. 4

3. Color pattern very characteristic: background rusty, and many flecks of dark pigment (Fig. 17), seta (TI3)4p1 present (as in Figs. 5-6), seta $P$ of abd. V absent ... multipunctatus - Color pattern different (Fig. 18), seta (TI3)4pl absent 
Table VIII. Differences between species of Sminthurus for the adult instar $(+=$ present, $-=$ absent, and $+/-=$ variable). An. app. is considered to be medium if it is about two times shorter than the mucro.

\begin{tabular}{|c|c|c|c|c|c|c|c|}
\hline & bourgeoisi & nigromaculatus & viridis & leucomelanus & bozoulensis & hispanicus & multipunctatus \\
\hline Secondary seta on SA3 & - & + & - & - & + & $+1-$ & + \\
\hline (FE2,3)ai5, (DE)3p, (AT)BBp & - & + & + & + & + & + & + \\
\hline (TI3)4p1 & + & + & - & - & $+1-$ & - & + \\
\hline Secondary setae on ventral tube & + & + & - & + & + & - & - \\
\hline Tunica present & + & + & + & $\stackrel{+}{\text { (reduced) }}$ & + & - & - \\
\hline $\begin{array}{l}\text { Seta P of abd. V } \\
\text { An. app. }\end{array}$ & $\begin{array}{c}- \\
\text { long }\end{array}$ & $\begin{array}{c}- \\
\text { long }\end{array}$ & $\frac{-}{\text { medium* }}$ & $\stackrel{+}{\text { medium }}$ & medium & $\begin{array}{c}+ \\
\text { short }\end{array}$ & short \\
\hline
\end{tabular}

* An. app. fairly short in specimens from Spain.

(Figs. 21-22), seta $\mathbf{P}$ of abd. $\mathrm{V}$ present (Fig. 25) ....... ........................... hispanicus $\mathrm{n} . \mathbf{s p}$.

4. Color pattern characteristic: background light yellow with a mediodorsal dark brownish-violet band from upper part of head to small abd. which is wider in anterior part of body (see Stach, 1956, pl. XXXIII, Fig. 6) .......... maculatus

- Color pattern characteristic: uniformly greenish-yellow except three black spots in transversal line on upper anal flap (Fig. 9) ................... bozoulensis n. sp.

- Color pattern different and not characteristic of species ... 5

5. Seta $P$ of abd. V present (as in Fig. 25) leucomelanus n. sp.

- Seta $P$ of abd. $V$ absent ....................6 6

6. Femur of mid- and hindlegs with 4 setae on generatrix $\mathrm{Ga}$ (Fig. 4) ................... bourgeoisi n. sp.

- Femur of mid- and hindlegs with 5 setae on generatrix $\mathrm{Ga}$ (as in Fig. 20) $\ldots \ldots \ldots \ldots \ldots \ldots \ldots \ldots \ldots \ldots \ldots \ldots$

7. Apical subcoxa of hindleg with a secondary seta (as in Fig. 20), seta (T13) 4 pl present (as in Figs. 5-6) ........ ........................... nigromaculatus

- Apical subcoxa of hindleg without secondary seta (as in Fig. 4), seta (TI3)4p1 absent (as in Figs. 21-22) ... viridis

If we consider secondary setae separately, not many of them may be used to discriminate the species (all the more so since it is not rare that secondary setae are variable). Therefore, a method for clustering setae is proposed here, and it will be applied to the secondary tibiotarsal chaetotaxy.

Setae on an area of the body can present a homeotypic relationship, e.g., a seta on the foreleg situated in a similar position as a seta on the median leg (homeotypy is also known under the expression "serial homology"). We can assess that setae on a same generatrix or on a same whorl have some homeotypic relationships. If we consider two homeotypic setae observed in the species studied, we can write the observations as vectors of the presence probabilities. I stated (Nayrolles, 1993a, $1993 \mathrm{~b}$ ) that the rate of presence of a seta is estimated by its occurrence. For instance, we can build up a table (Table IX) of occurrences for the secondary setae on the generatrices $\mathrm{Ga}$ and Gp (except FSa because on all legs this seta emerges at the 3rd st. without variability in all species). The occurrence of (TI1)4a1 in S. viridis is 0.5 in the 3rd st. and 1 in the 4th st. and ad. Therefore, for $S$. viridis, this seta is variable in the $3 \mathrm{rd}$ st. and always present from the 4th st. on. The occurrence in the 3rd st. was calculated as follows: I have observed 3 specimens with the seta present on both forelegs, 5 specimens with the seta only present on one foreleg, and 4 specimens with the seta absent on both forelegs; the value of occurrence is thus:

$\frac{(3 \cdot 2)+(5 \cdot 1)+(4 \cdot 0)}{2 \cdot(3+5+4)}=0.5$.

In Table IX, the vectors of observations are given in columns. If these vectors are the same, or present very close values, they can be gathered (vectorial addition). The setal clustering is relevant because it can be assessed that the homeotypic setae with similar values have the same information content. Homeotypic setae may also present an ordinal relationship. In Table IX, we compare the occurrences of two setae for the same row. If every occurrence of one seta is equal to or less than the occurrence of a second seta, then we can say that the second seta dominates the first, e.g. (TI3)3a dominates (TI3)4a1. In this case, setal clustering may also be worth while. The ordinal relationship corresponds to an ontophylogenetic gradient of setal presence 
Table IX. Occurrences of the secondary tibiotarsal setae on Ga and Gp, after data included in the chaetotaxic tables (Tables I-VII). The occurrences of FSa on the three pairs of tibiotarsi are not included in the table (in all species these setae emerge in 3rd st.). All occurrences of secondary tibiotarsal setae on $\mathrm{Ga}$ and $\mathrm{Gp}$ are equal to $\mathbf{0}$ at 1 st and 2 nd st. For every species, the occurrences in ad. are the same as in 4 th st. For further explanations see text.

\begin{tabular}{|c|c|c|c|c|c|c|c|c|c|c|c|c|c|c|}
\hline & \multicolumn{2}{|c|}{ TI1 } & \multicolumn{2}{|c|}{ TI2 } & \multicolumn{3}{|c|}{ TI3 } & \multicolumn{2}{|c|}{ TI1 } & \multicolumn{2}{|c|}{ TI2 } & \multicolumn{3}{|c|}{ TI3 } \\
\hline & $3 \mathbf{a}$ & $4 a 1$ & $3 a$ & $4 a 1$ & $2 a$ & $3 \mathbf{a}$ & $4 a 1$ & $3 p$ & $4 \mathrm{p} 1$ & $3 p$ & $4 \mathrm{pl}$ & $2 p$ & $3 p$ & $4 \mathrm{p} 1$ \\
\hline bourgeoisi 3rd st. & 0 & 0 & 0 & 0 & 0 & 0.6 & 0.3 & 0 & 0 & 0 & 0 & 0 & $\mathbf{0}$ & 0 \\
\hline bourgeoisi 4th st. & 1 & 1 & 1 & 1 & 1 & 1 & 1 & 1 & 1 & 1 & 1 & 1 & 1 & 1 \\
\hline nigromaculatus 3rd st. & 0 & 0 & 0 & 0 & $\mathbf{0}$ & 0.4 & 0.2 & 0 & 0 & 0 & $\mathbf{0}$ & 0 & 0 & 0 \\
\hline nigromaculatus 4th st. & 1 & 1 & 1 & 1 & 1 & 1 & 1 & 1 & 1 & 1 & 1 & 1 & 1 & 1 \\
\hline viridis 3rd st. & 0.8 & 0.5 & 0.8 & 0.6 & 1 & 1 & 0.7 & 0.6 & 0 & 0.5 & 0 & 0.5 & 0.2 & 0 \\
\hline viridis 4th st. & 1 & 1 & 1 & 1 & 1 & 1 & 1 & 1 & 1 & 1 & 0.5 & 1 & 1 & 0 \\
\hline leucomelanus 3rd st. & 1 & 0.4 & 1 & 0.6 & 1 & 1 & 0.6 & 0.7 & 0 & 0.6 & 0 & 0.6 & 0.3 & 0 \\
\hline leucomelanus 4th st. & 1 & 1 & 1 & 1 & 1 & 1 & 1 & 1 & 1 & 1 & 1 & 1 & 1 & 0 \\
\hline bozoulensis 3rd st. & 1 & 1 & 1 & 0.7 & 1 & 1 & 0.7 & 1 & $\mathbf{0}$ & 0.7 & 0 & 0.7 & 0.6 & 0 \\
\hline bozoulensis 4th st. & 1 & 1 & 1 & 1 & 1 & 1 & 1 & 1 & 1 & 1 & 1 & 1 & 1 & 0.6 \\
\hline hispanicus 3rd st. & 1 & 1 & 1 & 1 & 1 & 1 & 1 & 1 & 1 & 0.6 & 0 & 0 & 0 & 0 \\
\hline hispanicus 4th st. & 1 & 1 & 1 & 1 & 1 & 1 & 1 & 1 & 1 & 1 & 0.6 & 1 & 1 & 0 \\
\hline multipunctatus 3rd st. & 1 & 1 & 1 & 1 & 1 & 1 & 1 & 1 & 1 & 1 & 1 & 1 & 1 & 1 \\
\hline multipunctatus 4th st. & 1 & 1 & 1 & 1 & 1 & 1 & 1 & 1 & 1 & 1 & 1 & 1 & 1 & 1 \\
\hline
\end{tabular}

Table $X$. Values of chaetotaxic variables concerning the secondary tibiotarsal chaetotaxy. Averages of the setal occurrences are given; cf. Table IX, except for (TI.)FSpel (occurrences not given in Table IX). Example of the calculation: for the row "(TI.)3p in 3rd st.", we make the average, for each species, between the occurrences of setae (T11)3p, (TI2)3p, and (TI3) 3p at 3rd st.; e.g., for S. viridis, the values of these three setae are respectively (Table IX): $0.6,0.5$, and 0.2 , and the average is thus: $\frac{0.6+0.5+0.2}{3}=0.4$

\begin{tabular}{|c|c|c|c|c|c|c|c|}
\hline & bourgeoisi & nigromaculatus & viridis & leucomelanus & bozoulensis & hispanicus & multipunctatus \\
\hline $\begin{array}{l}\text { (TI.)FSpel in } 3 \text { rd st. } \\
\text { Secondary setae on Ga apart }\end{array}$ & $\mathbf{0}$ & 0.1 & 1 & 1 & 0.9 & 1 & 1 \\
\hline from $\mathrm{FSa}$, in 3rd st. & 0.1 & 0.1 & 0.8 & 0.8 & 0.9 & 1 & 1 \\
\hline (TI3)2p in 3rd st. & 0 & 0 & 0.5 & 0.6 & 0.7 & 0 & 1 \\
\hline (TI.)3p in $3 \mathrm{rd}$ st. & 0 & 0 & 0.4 & 0.5 & 0.8 & 0.5 & 1 \\
\hline (TI.) $4 \mathrm{p} 1$ in $3 \mathrm{rd}$ st. & 0 & 0 & 0 & 0 & 0 & 0.3 & 1 \\
\hline (TI.)4pl in 4th st. & 1 & 1 & 0.5 & 0.7 & 0.9 & 0.5 & 1 \\
\hline
\end{tabular}

probabilities. If the relationship between two homeotypic setae is neither similar (vectors with at least one pair of values being different) nor ordered, the clustering is not possible, e.g. between the setae (TI1)4pl and (TI3)2p. In Table IX, we can cluster all setae of $\mathrm{Ga}$, and for $\mathrm{Gp}$ the setae with the same position in the three tibiotarsi, viz. (TI.)3p or (TI.)4p1 - I recall that the period after TI means "all legs". Linear or nonlinear combinations can be performed on the vectors of setal occurrences (Nayrolles, 1993b). Consequently, chaetotaxic variables can be calculated.

The result is given in Table $X$. In this table, averages of occurrences were calculated rather than sums. Regarding the setae (TI.)FSpel, the secondary setae on Ga, (TI3) $2 p$, and (TI.)3p, the occur- 
rences are equal to 1 in every 4th st., so the differences between species involve only the 3 rd st. This is not the case for (TI.)4p1. The change in the instar of emergence for a seta or a set of setae fits with an evolutionary change. The polarization of these characters is beyond the scope of the present paper, and will be dealt with in a future survey.

Finally, the main result boils down to the great deal of attention that one should focus on the 3rd st. This instar displays most of the differences among species. The observation of this instar permits to ascertain the validity of a species, and above all, provides an array of characters suitable for a phylogenetic analysis.

\section{Acknowledgments}

I am indebted to the referees, Drs. J.M. Betsch, W.N. Ellis, and an anonymous reviewer, for their helpful suggestions. In particular, Dr. Betsch advised me to observe the setae of abdomen $V$ and compare the European species I studied with Snider's descriptions of North American species. The observation of abdomen $\mathrm{V}$ entails to uncover a character corresponding to the presence vs. absence of one seta which was shown to be very useful for distinguishing species.

\section{References}

Betsch, J.M., 1964. Collemboles Symphypléones des ÉtatsUnis. Première note. Revue Ecol. Biol. Sol, 1(3): 533-542.

Betsch, J.M., 1980. Eléments pour une monographie des Collemboles Symphypléones (Hexapodes, Aptérygotes). Mém. Mus. natn. Hist. nat., Paris (A, Zool.), 116: 1-227.

Betsch, J.M. \& M.C. Betsch-Pinot, 1984. Contribution à l'étude des Sminthurus (Collembola, Symphypleona). Annls. Soc. r. zool. Belg., 114(1): 71-81.

Christiansen, K.A. \& P.F. Bellinger, 1981. The Collembola of North America north of the Rio Grande, Part IV. Families Neelidae and Sminthuridae: 1043-1322 (Grinnell College, Iowa).
Ellis, W.N., 1974. The spring fauna of Collembola (Insecta) from Rhodos, with descriptions of some new taxa. Beaufortia, 22(292): 105-152.

Ellis, W.N., 1976. Autumn fauna of Collembola from Central Crete. Tijdschr. Ent., 119(8): 221-326.

Gisin, H., 1960. Collembolenfauna Europas: 1-312 (Mus. Hist. nat., Genève).

Nayrolles, P., 1989. Données nouvelles sur l'évolution ontogénétique des Collemboles Symphypléones. Nouv. Revue Ent., (N.S.) 6(3): 231-244.

Nayrolles, P., 1993a. A standardized description of European Sminthuridae (Collembola, Symphypleona), 1: genera Lipothrix, Gisinurus, and Caprainea. Bijdr. Dierk., 63(1): 43-60.

Nayrolles, P., 1993b. La biométrie des caractères discontinus d'après le revêtement appendiculaire des Collemboles Symphypléones, I. Sur quelques concepts nouveaux dans l'analyse numérique de la chétotaxie. Bull. Mus. natl. Hist. nat., Paris, (4e sér.) 15: 79-93.

Nayrolles, P., 1994. A standardized description of European Sminthuridae (Collembola, Symphypleona), 2: review of four species of the genera Allacma and Spatulosminthurus. Bijdr. Dierk., 64(3): 151-162.

Snider, R.J., 1969. New species of Deuterosminthurus and Sminthurus from Michigan (Collembola; Sminthuridae). Revue Ecol. Biol. Sol, 3(3): 357-376.

Snider, R.J., 1981. Sminthurus carolinensis, new species from South Carolina (Collembola: Sminthuridae). Florida Ent., 64(3): 417-424.

Snider, R.J., 1982. Redescription of Sminthurus floridanus MacGillivray, 1893 (Collembola: Sminthuridae). Florida Ent., 65(2): 221-227.

Snider, R.J., 1985. Sminthurus bivittatus, new species from the Southeastern United States (Collembola: Sminthuridae). Florida Ent., 68(4): 574-582.

Stach, J., 1956. The apterygotan fauna of Poland in relation to the world-fauna of this group of insects. Family: Sminthuridae: 1-287 (Polska Akad. Nauk Inst. Zool., Krakowie).

Wallace, M.M.H., 1973. The taxonomy and distribution of Sminthurus viridis and related species (Collembola: Sminthuridae) in western Europe and Morocco. Revue Ecol. Biol. Sol, 10(2): 211-224, pl. col. 1 .

Received: 17 March 1994

Revised: 24 August 1994 